\title{
Observed Tracer Fields Structuration by Middepth Zonal Jets in the Tropical Pacific
}

\author{
Audrey Delpech, Sophie Cravatte, Frédéric Marin, And Yves Morel \\ Laboratoire d'Etudes Géophysiques et d'Océanographie Spatiale, LEGOS - UMR 5566 CNRS/CNES/IRD/UPS, \\ Toulouse, France \\ ENZO GRONCHI \\ Limnological Institute, University of Konstanz, Konstanz, Germany \\ ELODIE KESTENARE \\ Laboratoire d'Etudes Géophysiques et d'Océanographie Spatiale, LEGOS - UMR 5566 CNRS/CNES/IRD/UPS, \\ Toulouse, France
}

(Manuscript received 27 May 2019, in final form 12 November 2019)

\begin{abstract}
The middepth ocean circulation in the tropical Pacific is dominated by sets of alternating eastward and westward jets. The origin and transport properties of these flow features remain in many ways an open question, all the more crucial since their usual underestimation in ocean global circulation models has been identified as a potential bias for the misrepresentation of the oxygen minimum zones. In this study, we analyze the water mass properties associated with these systems of jets using velocity and hydrographic sections. Data acquired during a dedicated cruise carried out in the western part of the basin and supplemented by crossequatorial sections from historical cruises in the central and eastern parts are analyzed. While it is confirmed that the near-equatorial jets carry oxygen anomalies, contributing to the ventilation of the eastern tropical Pacific, the data also revealed unexpected features. Tracer distributions (oxygen, salinity, and potential vorticity) show the presence of fronts extending from 500 to $3000 \mathrm{~m}$ and flanked by homogeneous regions. These structures define meridional staircase profiles that coincide with the alternating velocity profiles. Historical data confirm their presence in the off-equatorial deep tropical ocean with a zonal and temporal coherence throughout the basin. These observations support existing theoretical studies involving homogenization by isopycnic turbulent mixing in the formation of staircase profiles and maintenance of zonal jets. The effect of other processes on the equilibration of tracer structures is also discussed.
\end{abstract}

\section{Introduction}

Observation of the intermediate and deep ocean circulation is quite challenging because, unlike the surface currents that have been intensively studied thanks to satellite observations and other near-surface measurements (surface drifters, buoys, underway ship measurements), deeper observations are costly and sparse.

Our knowledge of this circulation in the tropical oceans has thus long been grounded on sections from hydrographic cruises mostly limited to a few degrees off the equator (Firing et al. 1998). In the tropical Pacific, pioneer cruises (Tsuchiya 1975; Eriksen 1981; Firing 1987;

Corresponding author: Audrey Delpech, audrey.delpech@ legos.obs-mip.fr
Firing et al. 1998; Rowe et al. 2000; Gouriou et al. 2001) revealed the presence of several persistent zonal currents below the thermocline in the near-equatorial band. Among them, the Tsuchiya jets are eastward currents found in the whole basin just below the thermocline between $2.5^{\circ}$ and $5^{\circ}$ from the equator, with intensities of $20-40 \mathrm{~cm} \mathrm{~s}^{-1}$ (Rowe et al. 2000). The North and South Equatorial Intermediate Countercurrents (NICC and SICC, respectively) are weaker and deeper eastward currents surrounding the westward Lower Equatorial Intermediate Current (L-EIC). They have been observed at different longitudes across the basin at $2^{\circ}$ from equator and below $600 \mathrm{~m}$. On their poleward side, the westward North and South Equatorial Intermediate Currents (NEIC and SEIC, respectively) are found at $3^{\circ}$. In addition to these meridionally alternating zonal currents, vertically 


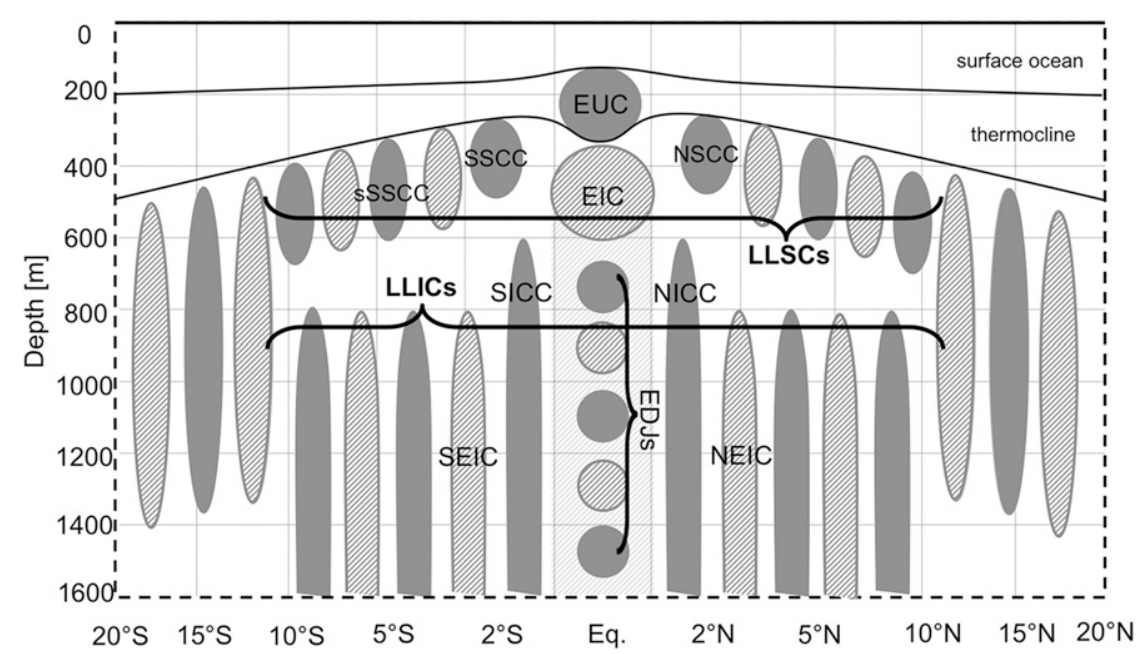

FIG. 1. Schematic of the different zonal jets systems listed in Table 1 as a function of latitude and depth $(\mathrm{m})$. Dark and light gray patches represent eastward and westward currents, respectively. For the sake of simplicity, surface currents have not been represented. Adapted from Ménesguen et al. (2019).

alternating eastward and westward jets, called equatorial deep jets (EDJs), are also found on the equator within $1^{\circ}$ (Ponte and Luyten 1989; Johnson et al. 2002), see also Fig. 1.

The advent of the Argo program provided a more comprehensive view with a basin-scale coverage. The 1000-m mean velocity maps deduced from Argo float drifts at their parking depth showed the zonal continuity of the L-EIC, SICC, NICC, NEIC, and SEIC and revealed that these currents are part of a broader system of meridionally alternating zonal jets extending to at least $15^{\circ}$ off-equator (Ascani et al. 2010; Cravatte et al. 2012; Ollitrault and Colin de Verdière 2014). Absolute geostrophic mean currents obtained from gridded temperature and salinity Argo products allowed the description of the vertical structure of these zonal currents in the whole tropical band from the surface to 2000-m depth (Qiu et al. 2013b; Cravatte et al. 2017). The arrival of new shipboard acoustic Doppler current profilers (S-ADCP) instruments with deeper range also extended our ability to observe subsurface currents to more than 1000-m depth (Qiu et al. 2017; Cravatte et al. 2017).

From all these studies, our current knowledge of the deep tropical Pacific Ocean circulation, can be summarized as follows [see also Ménesguen et al. (2019) and Galperin and Read (2019, chapter 3) for recent reviews]. The mean circulation appears to be organized in three main systems of zonal jets (Fig. 1 and Table 1):

- The low-latitude subsurface currents (LLSCs) are meridionally alternating zonal currents found between the thermocline and about 800-m depth, from the equator to about $18^{\circ}$, including the well-studied Tsuchiya jets, also called the Northern and Southern Subsurface Countercurrents (NSCC and SSCC) (Tsuchiya 1975). Their velocity reaches $20-40 \mathrm{~cm} \mathrm{~s}^{-1}$ in the core of the Tsuchiya jets but strongly decreases poleward. All these currents tend to get less dense from west to east and denser and deeper from the equator poleward (Rowe et al. 2000; Cravatte et al. 2017).

- The low-latitude intermediate currents (LLICs) are an apparently distinct set of meridionally alternating zonal currents, found from 700 to at least $2000 \mathrm{~m}$. Near the equator, this set includes the L-EIC, the SEIC and NEIC, and the SICC and NICC. The velocity of these currents reaches $10 \mathrm{~cm} \mathrm{~s}^{-1}$, and they change sign every $1.5^{\circ}$ (Cravatte et al. 2017).

- The EDJs are equatorially trapped, vertically alternating zonal jets with an amplitude of $10 \mathrm{~cm} \mathrm{~s}^{-1}$ and vertical wavelength close to $350 \mathrm{~m}$ (Leetmaa and Spain 1981). They are found to slowly propagate vertically with a period most recently estimated around 12 years (Youngs and Johnson 2015).

These currents are clearly visible and identifiable on time-averaged sections but not necessarily on snapshots where large differences from one cruise to another can be observed (Gouriou et al. 2006; Cravatte et al. 2017). Indeed, the equatorial region is subject to strong variability on many time scales. The predominant and best documented variability is at seasonal time scales: it is explained by the westward and downward propagation of an annual Rossby wave (Lukas and Firing 1985; Kessler and McCreary 1993) that can seasonally induce a reversal of the currents in the $2^{\circ} \mathrm{S}-2^{\circ} \mathrm{N}$ band (Marin et al. 2010; 
TABLE 1. Acronyms used for the denomination of the different currents.

\begin{tabular}{llll}
\hline \hline Short name & \multicolumn{1}{c}{ Long name } & Direction & Depth \\
\hline EUC & Equatorial Undercurrent & Eastward & Thermocline \\
EIC & Equatorial Intermediate Current & Westward & $\simeq 500 \mathrm{~m}$ \\
L-EIC & Lower Equatorial Intermediate Current & Westward & $>500 \mathrm{~m}$ \\
EDJ & Equatorial deep jets & Alternating & $>500 \mathrm{~m}$ \\
NSCC & Northern Subsurface Countercurrent & Eastward & $\simeq 350 \mathrm{~m}$ \\
& Northern Tsuchiya jet & Eastward & $\simeq 350 \mathrm{~m}$ \\
SSCC & Southern Subsuface Countercurrent & & $\simeq 450 \mathrm{~m}$ \\
SSSCC & Southern Tsuchiya jet & Eastward & \\
& Secondary Southern Subsurface Countercurrent & & Alternating \\
LLSCs & Secondary Southern Tsuchiya jet & Alternating & Thermocline-600 m \\
LLICs & Low-latitude subsurface currents & & $>700 \mathrm{~m}$ \\
\hline
\end{tabular}

Cravatte et al. 2012). Variability also exists at intraseasonal and interannual time scales but is much less documented.

Despite this progress in our description of the intermediate and deep circulation, our knowledge of these jets structures, their variability and properties is still far from being comprehensive, and several questions remain open.

The first unresolved question concerns the dynamics of these jets, and the processes leading to their formation and equilibration. Early studies attempted to explain the formation of the first Tsuchiya jets independently, invoking different mechanisms (Johnson and Moore 1997; McCreary et al. 2002; Hua et al. 2003; Marin et al. 2003; Furue et al. 2007, 2009). Later, two theoretical frameworks have been proposed to explain the formation of systems of alternating zonal jets (Ménesguen et al. 2019). In the first one, the main source of energy is coming from waves (either equatorially trapped waves or midlatitudes waves). Jets can be seen either as the result of instability of particular waves (Gill 1974; Hua et al. 2008; Ménesguen et al. 2009; d'Orgeville et al. 2007; Ascani et al. 2010, 2015) or nonlinear interactions and wave destabilization (Qiu et al. 2013a). The second one explains the emergence of such zonal structures as a result of the anisotropic inverse turbulent energy cascade on a beta plane (Rhines 1975; Berloff et al. 2009), extended to the equatorial regions in Theiss (2004). None of these studies have been able to account for the complexity of the zonal and vertical structures of the three systems of jets. Moreover, most ocean general circulation models (OGCMs) are not able to correctly simulate their structures and amplitudes, underlining that their formation mechanism is not fully understood.

The second unresolved question concerns the role of these jets in the redistribution of water properties across the Pacific Ocean. The misrepresentation of the intermediate circulation in biogeochemical coupled
OGCMs used in climate studies has been identified as a potential explanation for the bias in oxygen and nutrients concentration in the eastern equatorial Pacific (Dietze and Löptien 2013; Cabré et al. 2015) and in the Atlantic (Duteil et al. 2014). Some eastward jets advect oxygen-rich waters to the east, and contribute to the ventilation of the oxygen minimum zones (OMZ), found in the eastern tropical oceans from 100- to 900-m depth (Karstensen et al. 2008). For instance, Tsuchiya (1981) showed that the southern Tsuchiya jet carries oxygen-rich waters, originating from the Tasman Sea and reaching the equatorial band through the Coral and Solomon Seas. Wyrtki and Kilonsky (1984) were then the first to show from in situ observations a zonal signature of oxygen in the core of the EUC flowing inside the thermocline $(300 \mathrm{~m})$ from western well-ventilated regions to the eastern OMZ in the Pacific Ocean. Using hydrographic and current observations provided by cross-equatorial meridional sections of the World Ocean Circulation Experiment (WOCE) and the Tropical Ocean Atmosphere (TAO) project, Stramma et al. (2010) observed that in the central and eastern tropical Pacific Ocean (from $170^{\circ}$ to $95^{\circ} \mathrm{W}$ ), eastward subsurface currents (EUC, NSCC, SSCC, sSSCC) carry oxygen anomalies of $10-50 \mu \mathrm{mol} \mathrm{kg}^{-1}$ with respect to their neighboring westward currents (SEC, EIC). Similar results have been found in the Atlantic Ocean (Stramma et al. 2005, 2008, 2010; Brandt et al. 2008, 2012, 2015). These findings have also been confirmed by numerical simulations, which showed that EUC, SSCC, and sSSCC are crucial for the ventilation of oxygen minimum zones in both tropical Atlantic (Duteil et al. 2014) and Pacific (Montes et al. 2014) oceans. Farther off the equator, Czeschel et al. (2015) suggested that LLSCs have also a signature in oxygen in the far eastern Pacific.

At greater depths, there are fewer studies and most concern the Atlantic Ocean. The eastward EDJs have been shown to transport oxygen in the Atlantic (Brandt et al. 2008, 2012). Because of the oscillating nature of the EDJs at 
periods around 4.5 years in the Atlantic, and the expected phase lag between the eastward currents and the oxygen concentrations, oxygen maxima in eastward jets are not necessarily seen in snapshot measurements. The offequatorial NICC has also been identified as a potential supply path of oxygen-rich waters toward the North Atlantic OMZ (Stramma et al. 2005). In the Pacific Ocean, there are hints that the upper parts of the NICC and SICC may also supply oxygen eastward in the central and eastern parts of the basin (Stramma et al. 2010). However, the signature in oxygen of the intermediate and deeper jets in the western part of the basin has never been analyzed, and a global assessment of the three systems of zonal jets and the properties they carry across the basin is still missing.

The purpose of the present article is to document the structures of tracer fields in zonal jets in the tropical Pacific. The study is based on observations from a dedicated cruise in the western equatorial Pacific, CASSIOPEE, supplemented by high-resolution, crossequatorial sections from historical cruises in the central and eastern part of the basin.

The paper is organized as follows: the datasets used as well as the methodology for the computations of some diagnostics are described in section 2. Section 3 presents the main results obtained from the CASSIOPEE cruise, and reveals unexpected oxygen fronts in the eastward LLICs. Section 4 checks the consistency of these findings in other historical cruises and section 5 highlights the contribution of these findings to our understanding of jets dynamics and their role in the redistribution of water masses and tracers, in particular oxygen, at a basin scale.

\section{Data and methods}

This study is based on in situ data analysis. This section provides a complete description of the datasets and the postprocessings used.

\section{a. CASSIOPEE cruise description}

The CASSIOPEE ${ }^{1}$ oceanographic cruise took place onboard the French R/V L'Atalante in 2015 between 18 July and 24 August. The main motivation of this cruise was to describe the ocean circulation and water masses over the full depth of the ocean in the western equatorial Pacific. During the cruise, surface-to-bottom measurements of currents and properties have been acquired at 71 hydrological stations along three high-resolution meridional sections: one at $165^{\circ} \mathrm{E}$ between $10^{\circ} \mathrm{S}$ and $2^{\circ} \mathrm{N}$ with a meridional resolution of $0.33^{\circ}$, and two others

\footnotetext{
${ }^{1}$ https://doi.org/10.17600/15001200.
}

between the Papua New Guinea coast and $2^{\circ} \mathrm{N}$ with a meridional resolution of $0.5^{\circ}$ respectively at $157.5^{\circ} \mathrm{E}$ and at $152.5^{\circ} \mathrm{E}$ (see the cruise plan on Fig. 2). The $165^{\circ} \mathrm{E}$ section will be the reference section for the description of currents and their properties. The $152.5^{\circ}$ and $157.5^{\circ} \mathrm{E}$ sections will be used to investigate the zonal continuity of the currents and their properties. During this cruise, the following measurements were performed.

\section{1) Currents}

Horizontal currents were recorded along the ship track with two S-ADCP OS-38 kHz and OS- $150 \mathrm{kHz}$, with typical vertical ranges of 1100 and $350 \mathrm{~m}$, respectively. S-ADCP data were processed and calibrated using the CODAS software. Surface-to-bottom profiles of velocities were additionally measured at each hydrological station with two lowered ADCP (L-ADCP) attached to the rosette. The configuration used comprised a downward-looking $150-\mathrm{kHz}$ L-ADCP and an upward-looking $300-\mathrm{kHz}$ L-ADCP. Data were processed with the version 10.16 of the LDEO software, using time-averaged S-ADCP velocities during stations and bottom-reference velocity profiles as external constraints for the inversion (Visbeck 2002). The resulting vertical profiles of zonal and meridional velocities have a vertical resolution of $10 \mathrm{~m}$.

\section{2) Temperature, SALINITy, AND OXYGEN}

During the 71 stations, vertical profiles of temperature, salinity and dissolved oxygen were measured from the surface to the bottom using two $24-\mathrm{Hz}$ CTD (SBE911 + sensor) mounted on the rosette. CTD data were corrected and adjusted to the salinity samples with the CADHYAC software (Kermabon et al. 2015) and reduced to a $1-\mathrm{m}$ vertical resolution. Dissolved oxygen sensor data were adjusted by comparison with a Winkler titration determination of water samples (Langdon 2010; Uchida et al. 2010; Saout Grit et al. 2015).

When needed, data were regridded using 1D linear interpolation and smoothed using running Hanning filters of $50 \mathrm{~m}$ to reduce small-scale vertical noise.

\section{b. Supplementary historical cruises}

To extend the results found with the CASSIOPEE dataset, independent and complementary datasets from the World Ocean Circulation Experiment (WOCE) provided by the Clivar and Carbon Hydrographic Data Office $\left(\mathrm{CCHDO}^{2}\right)$ are considered. Only full-depth, crossequatorial, and high-resolution (at least $0.5^{\circ}$ ) sections have been selected, except for the equatorial profiles. The list of the cruise sections we used is given in Table 2.

\footnotetext{
${ }^{2}$ https://cchdo.ucsd.edu/.
} 


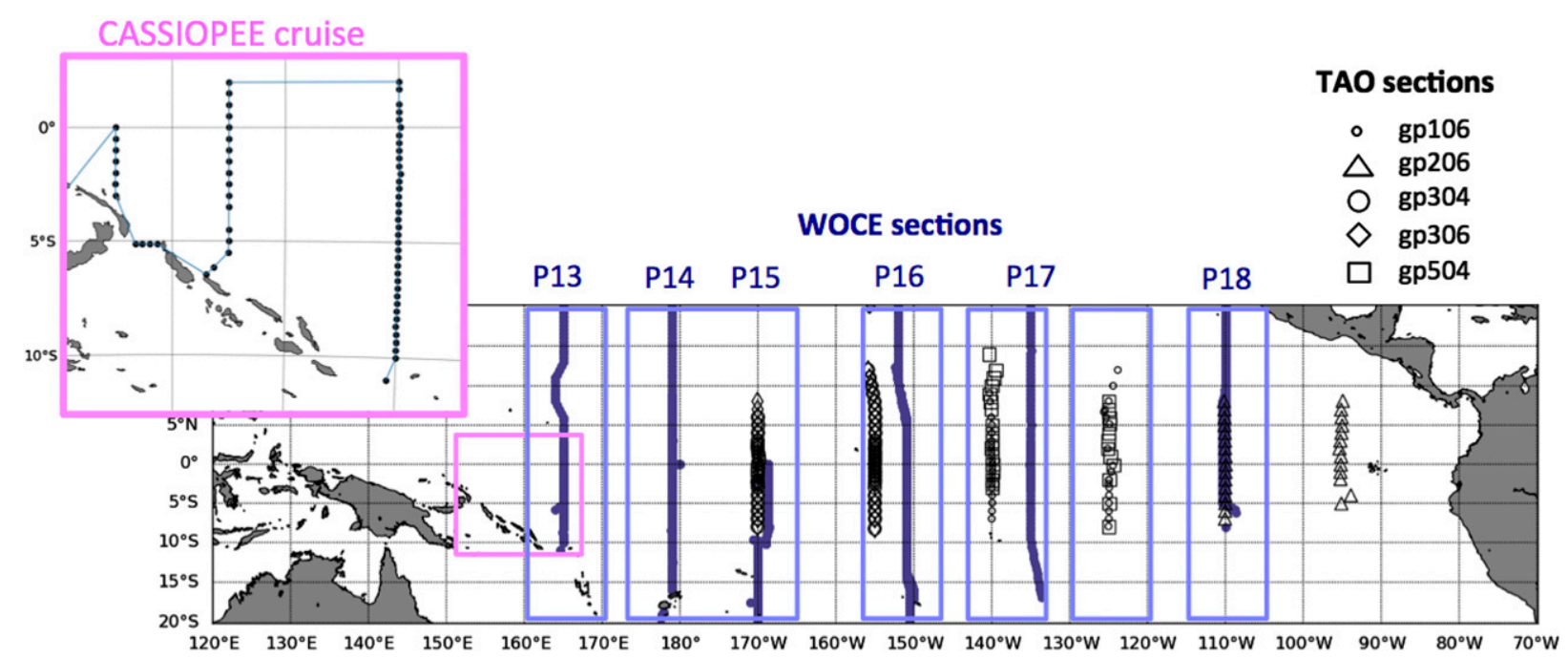

FIG. 2. Cruise tracks used in this study. Blue lines represent the WOCE sections and their labels. Black symbols represent the different TAO cruises. The pink square box gives the detailed positions of the hydrological stations of the CASSIOPEE cruise. The blue boxes represent the boxes used for Fig. 10.

In addition, data from the TAO project cruises given in Table 3, which contributed to maintaining approximately 70 moorings in the equatorial Pacific, were used. On a few of these cruises, from 2004 to 2008, dissolved oxygen was additionally measured to $1000-\mathrm{m}$ depth (Stramma et al. 2010). Though not full depth, these data are still relevant for this study, since they provide repeated cross-equatorial meridional sections with temperature, salinity, dissolved oxygen, and S-ADCP velocity.

\section{c. Climatology products}

\section{1) ARgo VELOCITY PRODUCTS}

The Argo-based deep displacement atlas $\left(\mathrm{ANDRO}^{3}\right.$; Ollitrault and Rannou 2013) gives, for each Argo float, an estimate of the velocity at the float parking depth between two dives, resulting in an approximately 10day averaged estimation. In addition, we used a product of mean absolute geostrophic velocity, hereafter called the CR17 product (Cravatte et al. 2017). It is based on two components: a vertical shear of zonal geostrophic velocity computed off and at the equator following the method presented by Picaut and Tournier (1991), from a mean high-resolution Argo gridded temperature and salinity climatology at $1 / 6^{\circ}$ resolution (Roemmich and Gilson 2009), and a mean 1000-m Argo drift as the reference velocity at $1000 \mathrm{~m}$ for vertically integrating the geostrophic shear (Cravatte et al. 2012).

\footnotetext{
${ }^{3}$ https://doi.org/10.17882/47077.
}

\section{2) Atlas of HydrologicAl PROPERTIES}

The CSIRO Atlas of Regional Seas $\left(\mathrm{CARS}^{4}\right)$ provided by the Commonwealth Scientific and Industrial Research Organisation (CSIRO) is a climatology of seasonal ocean hydrographic properties (temperature, salinity, and oxygen). This climatology is particularly well adapted for the southwestern Pacific Ocean because it includes data from many regional cruises, moored arrays, and autonomous profilers (Ridgway et al. 2002).

\section{d. Computation of physical and thermodynamical variables}

Thermodynamical variables such as potential density, Absolute Salinity, and Conservative Temperature were computed thanks to the Python toolbox Gibbs Seawater (GSW-python ${ }^{5}$ ), which implements the Thermodynamics Equations of State (IOC et al. 2010).

Potential vorticity (PV) is a key quantity to analyze the dynamical properties of jets (Baldwin et al. 2007). It is a conservative tracer under adiabatic conditions and can help to characterize water masses. It was here computed for the CASSIOPEE cruise sections assuming the dynamics is two-dimensional and neglecting the zonal derivative of meridional velocity.

Ertel's PV, taking into account Boussinesq approximation, can be expressed as (Müller 2006)

\footnotetext{
${ }^{4} \mathrm{http} / / /$ www.marine.csiro.au/ dunn/cars2009/.

${ }^{5}$ https://teos-10.github.io/GSW-Python/intro.html.
} 
TABLE 2. WOCE sections used for the study. Label for the L-ADCP data: a.: available, p.a.: partially available, n.a.: not available. In bold is the CASSIOPEE cruise.

\begin{tabular}{|c|c|c|c|c|c|c|c|}
\hline Section & Year & Dates & Longitude & Latitude range & Resolution & $\mathrm{R} / \mathrm{V}$ & L-ADCP \\
\hline $\mathrm{P} 13$ & 1992 & 4 Aug-21 Oct & $165^{\circ} \mathrm{E}$ & $5^{\circ} \mathrm{S}-10^{\circ} \mathrm{N}$ & $>0.5^{\circ}$ & John V. Vickers & p.a. \\
\hline $\mathrm{P} 13$ & 2011 & 15 May-26 Aug & $165^{\circ} \mathrm{E}$ & $5^{\circ} \mathrm{S}-10^{\circ} \mathrm{N}$ & $0.5^{\circ}$ & Ryofu Maru & n.a. \\
\hline P13 & 2015 & 18 Jul-24 Aug & $165^{\circ} \mathbf{E}$ & $\mathbf{1 0}^{\circ} \mathbf{S}-\mathbf{2}^{\circ} \mathbf{N}$ & $\mathbf{0 . 3 3}^{\circ}$ & L'Atalante & a. \\
\hline $\mathrm{P} 14$ & 1993 & 5 Jul-2 Sep & $179^{\circ} \mathrm{W}$ & $15^{\circ} \mathrm{S}-20^{\circ} \mathrm{N}$ & $0.5^{\circ}$ & Thomas G. Thompson & p.a. \\
\hline $\mathrm{P} 14$ & 2007 & 8 Oct -20 Nov & $179^{\circ} \mathrm{W}$ & $15^{\circ} \mathrm{S}-8^{\circ} \mathrm{N}$ & $0.5^{\circ}$ & Mirai & n.a. \\
\hline $\mathrm{P} 15$ & 2001 & 24 May-8 Jul & $170^{\circ} \mathrm{W}$ & $20^{\circ} \mathrm{S}-0^{\circ}$ & $0.5^{\circ}$ & Franklin & n.a. \\
\hline $\mathrm{P} 15$ & 2009 & 3 Feb-24 Mar & $170^{\circ} \mathrm{W}$ & $20^{\circ} \mathrm{S}-0^{\circ}$ & $0.5^{\circ}$ & Surveyor & n.a. \\
\hline $\mathrm{P} 15$ & 2016 & 26 Apr-22 Jun & $170^{\circ} \mathrm{W}$ & $20^{\circ} \mathrm{S}-0^{\circ}$ & $0.5^{\circ}$ & Investigator & a. \\
\hline $\mathrm{P} 16$ & 1991 & 31 Aug-1 Oct & $151^{\circ} \mathrm{W}$ & $15^{\circ} \mathrm{S}-5^{\circ} \mathrm{N}$ & $0.5^{\circ}$ & Washington & p.a. \\
\hline P16 & 2006 & 13 Feb-29 Mar & $151^{\circ} \mathrm{W}$ & $5^{\circ} \mathrm{S}-15^{\circ} \mathrm{N}$ & $>0.5^{\circ}$ & Thomas G. Thompson & a. \\
\hline P16 & 2015 & 10 Apr-13 May & $151^{\circ} \mathrm{W}$ & $15^{\circ} \mathrm{S}-5^{\circ} \mathrm{N}$ & $0.5^{\circ}$ & Ronald H. Brown & n.a. \\
\hline $\mathrm{P} 17$ & 1991 & 31 May-11 Jul & $135^{\circ} \mathrm{W}$ & $5^{\circ} \mathrm{S}-20^{\circ} \mathrm{N}$ & $0.5^{\circ}$ & Washington & p.a. \\
\hline P18 & 1994 & 26 Jan-27 Apr & $110^{\circ} \mathrm{W}$ & $5^{\circ} \mathrm{S}-20^{\circ} \mathrm{N}$ & $0.5^{\circ}$ & Discover & p.a. \\
\hline P18 & 2007 & 15 Dec 2007-23 Feb 2008 & $110^{\circ} \mathrm{W}$ & $5^{\circ} \mathrm{S}-20^{\circ} \mathrm{N}$ & $0.5^{\circ}$ & Ronald H. Brown & a. \\
\hline $\mathrm{P} 18$ & 2016 & 19 Nov-3 Feb & $110^{\circ} \mathrm{W}$ & $15^{\circ} \mathrm{S}-5^{\circ} \mathrm{N}$ & $0.5^{\circ}$ & Ronald H. Brown & a. \\
\hline
\end{tabular}

$$
Q=(\xi+\mathbf{f}) \cdot \frac{\nabla \gamma}{\rho_{0}}
$$

where $\boldsymbol{\xi}$ is the vorticity, $\mathbf{f}$ the Coriolis parameter, $\gamma$ the neutral density (McDougall 1988; Eden and Willebrand 1999), and $\rho_{0}$ a reference in situ density. Note that PV at rest is

$$
Q_{0}=f \frac{\partial_{z} \bar{\gamma}}{\rho_{0}}
$$

with $f$ the vertical component of the planetary vorticity and $\bar{\gamma}$ the neutral density profile at rest. PV at rest is dominated by the variation of stratification with depth. The isopycnic variation of Ertel's PV is thus masked by this strong background variation and not easy to analyze on vertical sections. However, alternative PV can be defined, having the same properties (Lagrangian conservation for adiabatic motions, inversion properties to derive the circulation associated with the PV distribution, under geostrophic assumption). Following Morel et al. (2019), we define a rescaled PV as

$$
Q^{*}=(\boldsymbol{\xi}+\mathbf{f}) \cdot \nabla[G(\gamma)],
$$

where $G$ is a function chosen so that $Q_{0}^{*}$ does not depend on $z$. A simple solution is to choose $G$ so that $G[\bar{\gamma}(z)]=z$ and $Q_{0}^{*}=f$. The rescaled PV has dimensions of vorticity. It is difficult to evaluate the vertical profile associated with the ocean at rest, but rescaling by a typical density profile chosen among the observations yields the expected result and allows to get rid of the signature of the pycnocline. Here we have chosen the profiles at $6.66^{\circ} \mathrm{S}$ for section $165^{\circ} \mathrm{E}$ and at $4.33^{\circ} \mathrm{S}$ for section $157.5^{\circ} \mathrm{E}$. Our results are not sensitive to the choice of these profiles.

\section{Zonal jets and tracer structures in the southwestern equatorial Pacific: The CASSIOPEE cruise}

\section{a. Currents structure and variability}

The structure of the currents during the CASSIOPEE cruise is shown using the full-depth L-ADCP data (Fig. 3). Although these transects are snapshots of the

\begin{tabular}{|c|c|c|c|c|c|c|}
\hline Name of the cruise & Dates & Longitude & Latitude range & Depth & Resolution & S-ADCP \\
\hline GP1-06-KA & January 2006-February 2006 & $140^{\circ} \mathrm{W}$ & $7.5^{\circ} \mathrm{S}-9.5^{\circ} \mathrm{N}$ & $1000 \mathrm{~m}$ & $0.5^{\circ}$ & a. \\
\hline GP1-06-KA & January 2006-February 2006 & $125^{\circ} \mathrm{W}$ & $7.5^{\circ} \mathrm{S}-8.5^{\circ} \mathrm{N}$ & $1000 \mathrm{~m}$ & $0.5^{\circ}$ & a. \\
\hline GP2-06-KA & April 2006 & $110^{\circ} \mathrm{W}$ & $7^{\circ} \mathrm{S}-8^{\circ} \mathrm{N}$ & $1000 \mathrm{~m}$ & $0.5^{\circ}$ & a. \\
\hline GP2-06-KA & April 2006 & $95^{\circ} \mathrm{W}$ & $4^{\circ} \mathrm{S}-6^{\circ} \mathrm{N}$ & $1000 \mathrm{~m}$ & $0.5^{\circ}$ & a. \\
\hline GP3-04-KA & June 2004-July 2004 & $155^{\circ} \mathrm{W}$ & $8^{\circ} \mathrm{S}-9.5^{\circ} \mathrm{N}$ & $1000 \mathrm{~m}$ & $0.5^{\circ}$ & a. \\
\hline GP3-04-KA & June 2004-July 2004 & $140^{\circ} \mathrm{W}$ & $7.5^{\circ} \mathrm{S}-9.5^{\circ} \mathrm{N}$ & $1000 \mathrm{~m}$ & $0.5^{\circ}$ & a. \\
\hline GP3-06-KA & June 2006 & $170^{\circ} \mathrm{W}$ & $8^{\circ} \mathrm{S}-8^{\circ} \mathrm{N}$ & $1000 \mathrm{~m}$ & $0.5^{\circ}$ & a. \\
\hline GP3-06-KA & June 2006 & $155^{\circ} \mathrm{W}$ & $8^{\circ} \mathrm{S}-9.5^{\circ} \mathrm{N}$ & $1000 \mathrm{~m}$ & $0.5^{\circ}$ & a. \\
\hline GP5-04-KA & September 2004 & $140^{\circ} \mathrm{W}$ & $2^{\circ} \mathrm{S}-9^{\circ} \mathrm{N}$ & $1000 \mathrm{~m}$ & $0.5^{\circ}$ & a. \\
\hline GP5-04-KA & September 2004 & $125^{\circ} \mathrm{W}$ & $8^{\circ} \mathrm{S}-10^{\circ} \mathrm{N}$ & $1000 \mathrm{~m}$ & $0.5^{\circ}$ & a. \\
\hline
\end{tabular}
ocean circulation, which is known to vary on a large

TABLE 3. TAO sections used for the study sampled on board Ka'imimoana. Label for the S-ADCP data: a.: available, n.a.: not available. 
range of time scales (from diurnal to interannual), most of the important features of the mean tropical circulation and its organization into zonal jets can be identified. They are described below for the three sections, from the equator poleward and from the surface to the bottom.

\section{1) EQUATORIAL SYSTEM}

At the equator, strong positive velocities (up to $1 \mathrm{~m} \mathrm{~s}^{-1}$ ) are found in the upper layers down to $300 \mathrm{~m}$ on all sections in a latitudinal band extending from $2.5^{\circ} \mathrm{S}$ to at least $2^{\circ} \mathrm{N}$ (Fig. 4a). This is not typical of this region of the Warm Pool, where the mean surface current in August is expected to be very weak (Reverdin et al. 1994). Note however, that the cruise coincides with the development of the strongest El Niño event of the early twenty-first century and with a series of strong westerly wind events (McPhaden 2015). This unusual upperocean velocity structure is likely related to the anomalous wind forcing during the cruise (not shown).

In the thermocline, a core of positive velocity (about $50 \mathrm{~cm} \mathrm{~s}^{-1}$ ) is found at 200-250-m depth in all sections and extends from $1.5^{\circ} \mathrm{S}$ to $1.5^{\circ} \mathrm{N}$ (Fig. 4). This corresponds to the EUC (Johnson et al. 2002). Just below the EUC, a core of westward current $\left(15 \mathrm{~cm} \mathrm{~s}^{-1}\right)$ is found from 250 to $400 \mathrm{~m}$ between $1.5^{\circ} \mathrm{S}$ and $1.5^{\circ} \mathrm{N}$ at $157.5^{\circ}$ and $165^{\circ} \mathrm{E}$. It corresponds to the EIC.

From 500 to $2500 \mathrm{~m}$ the flow on the equator is predominantly westward with speeds up to $20 \mathrm{~cm} \mathrm{~s}^{-1}$, corresponding to the climatological L-EIC. Superimposed on this large-vertical-scale westward flow is the smaller-scale EDJ pattern with a vertical wavelength of about $300 \mathrm{~m}$ and with an amplitude of 6-12 $\mathrm{cm} \mathrm{s}^{-1}$ (Ponte and Luyten 1989; Youngs and Johnson 2015). The EDJs are most evident in the full velocity field at $157.5^{\circ} \mathrm{E}$ (Fig. 3a); their zonal continuity from there to $165^{\circ} \mathrm{E}$ emerges when a vertical wavenumber bandpass filter is used to isolate them from the larger vertical scale flow [section $3 b(2)$ ].

\section{2) EXTRAEQUATORIAL SYSTEMS}

Off the equatorial band and below the thermocline, subsurface countercurrents (SCCs) with positive velocities above $20 \mathrm{~cm} \mathrm{~s}^{-1}$ are found at $2^{\circ} \mathrm{S}-400 \mathrm{~m}$ and $5^{\circ} \mathrm{S}$ $500 \mathrm{~m}$, also referred to as primary and secondary Tsuchiya jets (Tsuchiya 1975; Gouriou and Toole 1993). The primary SCC at $2^{\circ} \mathrm{S}$ is seen on sections $165^{\circ}$ and $157.5^{\circ} \mathrm{E}$ but not at $152.5^{\circ} \mathrm{E}$. Indeed, it has been suggested that it originates at the Solomon Strait (Tsuchiya 1981), which is located at $156^{\circ} \mathrm{E}$ (just east of this section). The secondary Tsuchiya jet is also visible on the two easternmost sections $\left(165^{\circ}\right.$ and $\left.157.5^{\circ} \mathrm{E}\right)$. A core of eastward velocity of amplitude $12 \mathrm{~cm} \mathrm{~s}^{-1}$ is also seen at $10^{\circ} \mathrm{S}-500 \mathrm{~m}$ deep on section $165^{\circ} \mathrm{E}$ (Fig. 3).
At intermediate depths, six intermediate zonal jets are observed between $1.5^{\circ}$ and $10^{\circ} \mathrm{S}$, with eastward-flowing jets at $1.5^{\circ}, 4^{\circ}$, and $7^{\circ} \mathrm{S}$ and westward-flowing jets at $2.5^{\circ}$, $6^{\circ}$, and $8^{\circ} \mathrm{S}$, extending from $800 \mathrm{~m}$ down to $3000 \mathrm{~m}$ where the bottom topography allows it, slightly sloping toward the equator with depth (Fig. 3a). These jets have a good zonal coherence and can be followed on sections $157.5^{\circ}$ and $152.5^{\circ} \mathrm{E}$ from the western boundary. The eastward jets at $1.5^{\circ} \mathrm{N}$ and $1.5^{\circ} \mathrm{S}$ are generally referred to as the NICC and SICC (Firing et al. 1998).

At greater depths (below $3000 \mathrm{~m}$ ), the circulation appears more constrained by the local topography. The eastward jet at $7^{\circ} \mathrm{S}$ extends down to $3500 \mathrm{~m}$ and seems to be channeled between two local ridges at $8.5^{\circ}$ and $5.5^{\circ} \mathrm{S}$. Intense instantaneous velocities (up to $15 \mathrm{~cm} \mathrm{~s}^{-1}$ ) are still observed at the bottom or along ridges.

\section{3) COMPARISON With THE MEAN CLIMATOLOGY}

Figures $3 \mathrm{a}$ and $3 \mathrm{~b}$ compare the meridional sections of L-ADCP zonal velocities measured during the CASSIOPEE cruise, and the corresponding sections of zonal absolute geostrophic velocities from the CR17 product corresponding to the mean for August, the month of the cruise. Figure $3 \mathrm{c}$ shows meridional profiles of zonal velocities averaged over the isopycnal layers 1027.0 $1027.6 \mathrm{~kg} \mathrm{~m}^{-3}$ (corresponding approximately to 500 $1500 \mathrm{~m}$ ) for the same products.

In the western part of the basin, where the cruise was carried out, the two systems of zonal jets, the LLSC and the LLIC, are not clearly distinct, as is the case farther east (not shown). They appear as continuous slanted features in meridional-depth sections. As described above, the CASSIOPEE observations capture most of the mean subthermocline jets: the EIC, the first and second Tsuchiya jets, but the third eastward LLSC current located at $8.5^{\circ} \mathrm{S}$ in the annual climatology (Cravatte et al. 2017) is not fully observed, although a local velocity extremum is present (Fig. 3c). Below, the CASSIOPEE observations capture well the six mean intermediate jets between $10^{\circ}$ and $1.5^{\circ} \mathrm{S}$, both in position and amplitude. The strongest differences between the currents observed during the CASSIOPEE cruise and the annual mean from Argo product are observed near the equator, between $2^{\circ} \mathrm{S}$ and $2^{\circ} \mathrm{N}$, in the depth range 500-1500 m, where velocities are weak and variable in direction in the annual climatology but much stronger and westward during the CASSIOPEE cruise and in August climatology (Fig. 3c, sections $157.5^{\circ}$ and $165^{\circ} \mathrm{E}$ ). Such a result is compatible with the presence of a strong seasonal cycle in zonal currents near the equator as revealed by observations (Gouriou et al. 2006; Cravatte et al. 2012) or in models (Marin et al. 2010). This seasonal cycle has been explained by the 
$152.5^{\circ} \mathrm{E}$

a)
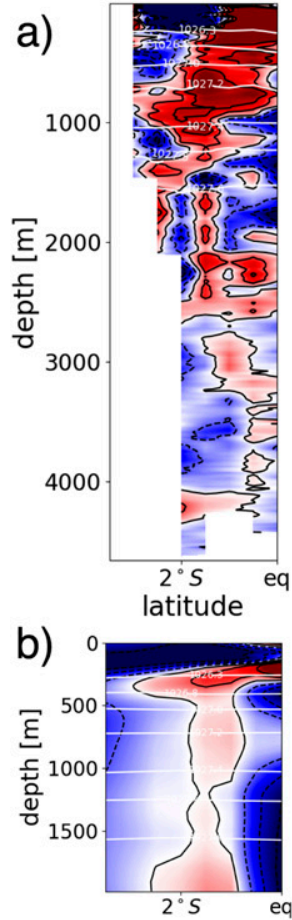

$157.5^{\circ} \mathrm{E}$
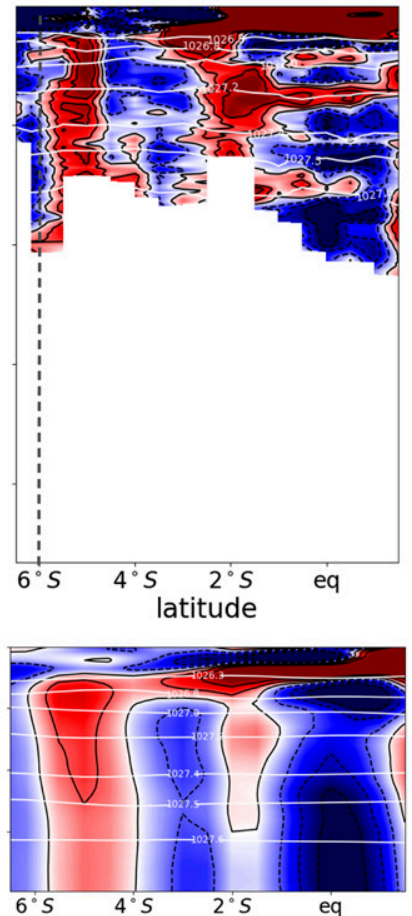

$165^{\circ} \mathrm{E}$

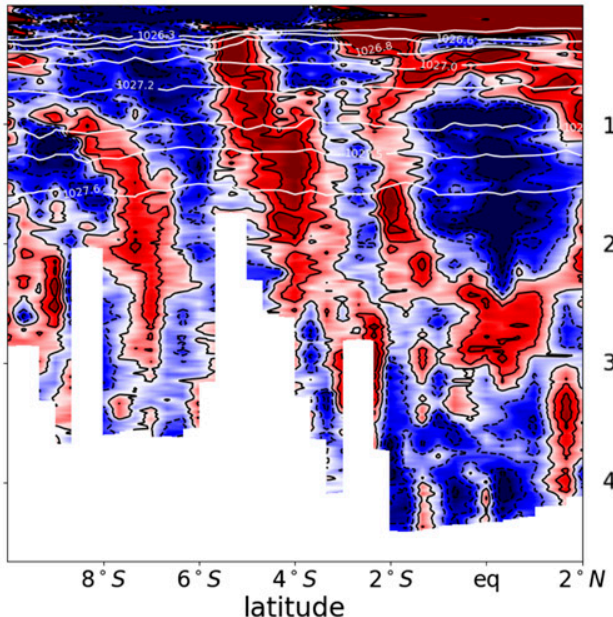

velocity $[\mathrm{cm} / \mathrm{s}]$
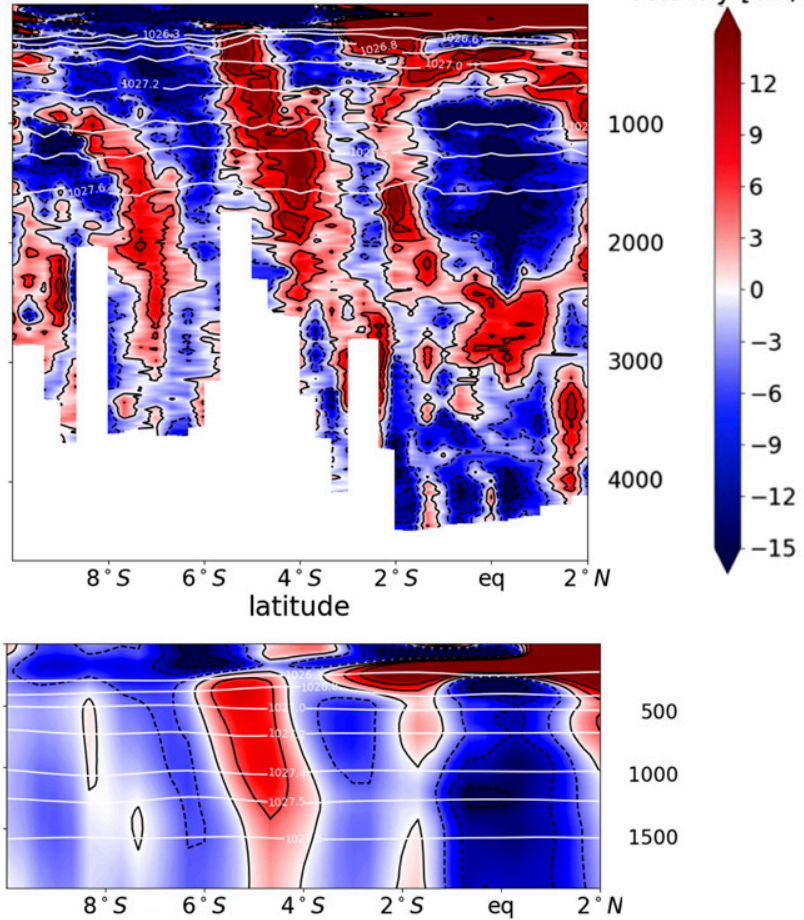

c)

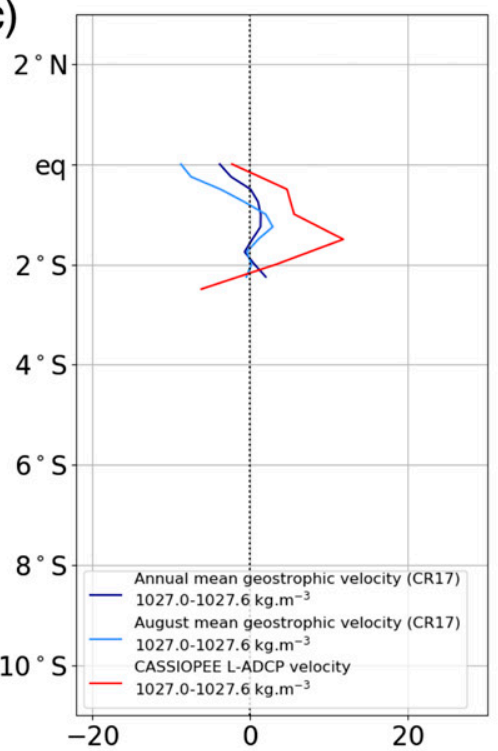

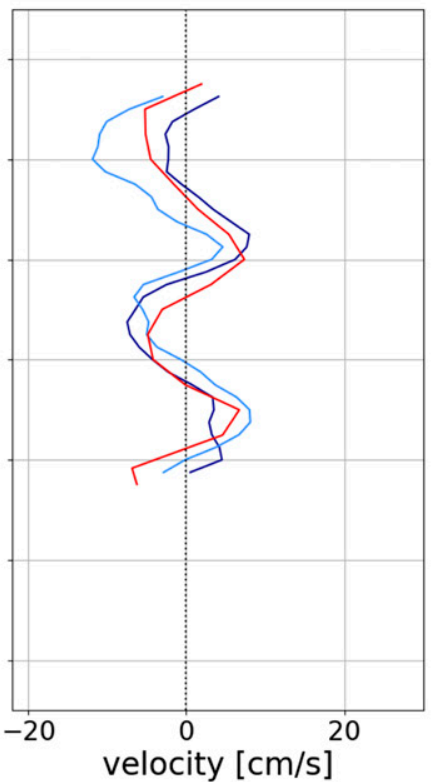

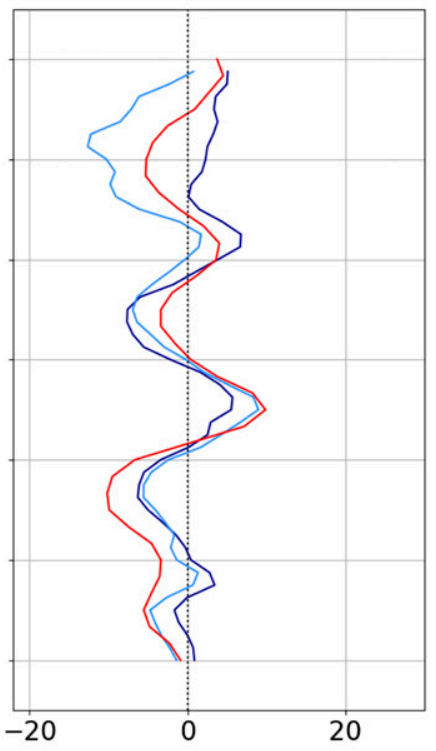

FIG. 3. (a) CASSIOPEE zonal velocity sections from L-ADCP measurements. Contours are every $5 \mathrm{~cm} \mathrm{~s}^{-1}$. Velocities are filtered in the vertical using a Hanning filter of $50 \mathrm{~m}$. White contours represent density levels. The gray dashed line separates the two western boundary stations of section $157.5^{\circ} \mathrm{E}$ at $6^{\circ}$ and $6.5^{\circ} \mathrm{S}$ (Fig. 2). (b) Absolute geostrophic zonal velocity sections from CR17 (Cravatte et al. 2017) between the surface and $2000 \mathrm{~m}$ for the month of August. The colorbar is the same as the one used for (a). (c) Comparison between CASSIOPEE LADCP (red) and Argo geostrophic zonal velocities (CR17) within the isopycnal layer 1027.0-1027.6 kg m ${ }^{-3}$ (approximately 500-1500 m). Light blue lines represent Argo geostrophic velocities for August, and dark blue lines represent Argo annual mean velocities. Velocities have been filtered using a running Hanning mean of $1^{\circ}$ of latitude. In (a)-(c), the left, center, and right panels correspond to sections $152.5^{\circ}, 157.5^{\circ}$, and $165^{\circ} \mathrm{E}$, respectively. 
$152.5^{\circ} \mathrm{E}$
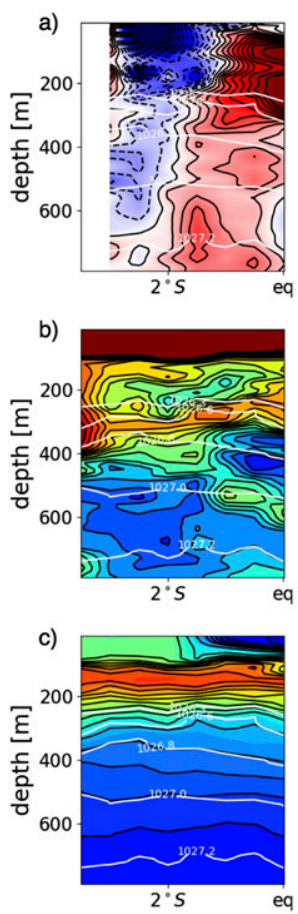

$157.5^{\circ} \mathrm{E}$
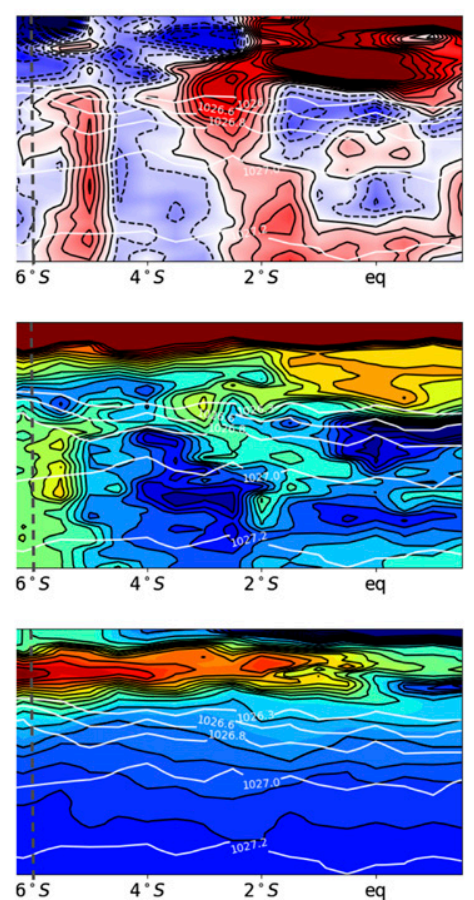

$165^{\circ} \mathrm{E}$
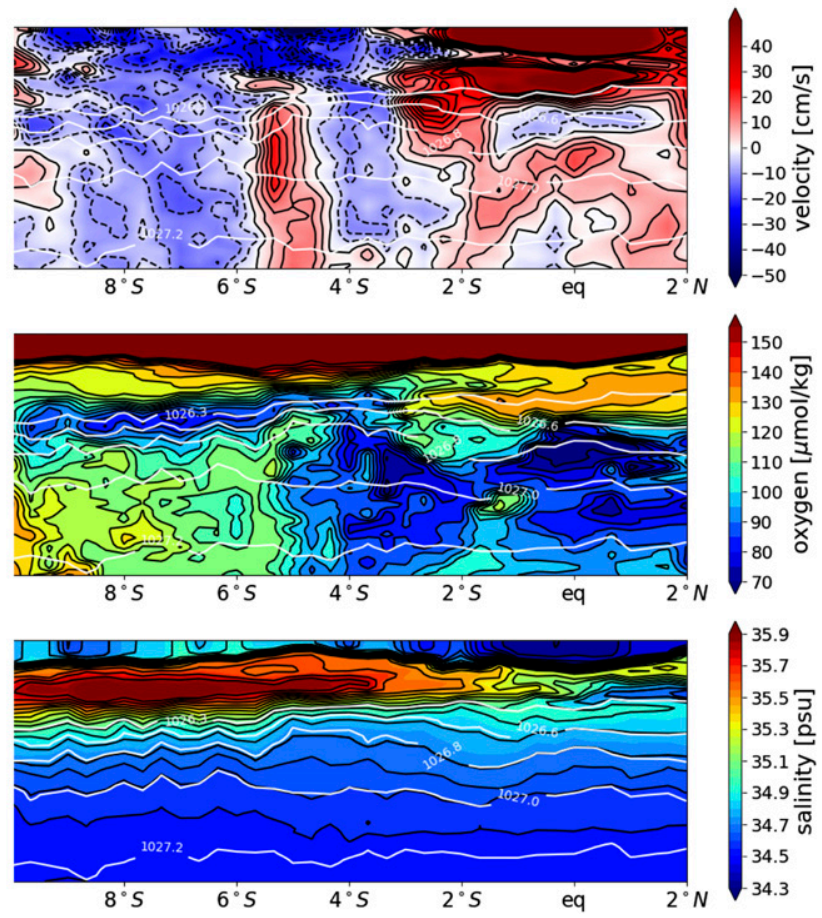

FIG. 4. CASSIOPEE sections zoomed in between 0 and $800 \mathrm{~m}$. (a) L-ADCP zonal velocity along the three sections of the CASSIOPEE cruise: (left) $152.5^{\circ} \mathrm{E}$, (center) $157.5^{\circ} \mathrm{E}$, (right) $165^{\circ} \mathrm{E}$. Contours are every $5 \mathrm{~cm} \mathrm{~s}^{-1}$. Data have been filtered using a vertical Hanning filter over $50 \mathrm{~m}$. White lines represent density contours. (b) As in (a), but for oxygen concentration. Contours are every $5 \mu \mathrm{mol} \mathrm{kg}^{-1}$. (c) As in (a), but for salinity. Contours are every $0.005 \mathrm{psu}$. The gray dashed line separates the two western boundary stations of section $157.5^{\circ} \mathrm{E}$ at $6^{\circ}$ and $6.5^{\circ} \mathrm{S}$ (Fig. 2).

westward and downward propagation of an annual Rossby wave, forced near the surface by the seasonally varying wind stress (Lukas and Firing 1985; Kessler and McCreary 1993). This wave induces large velocity anomalies with energy propagating annually from the eastern upper layers to the western deep layers (see Marin et al. 2010, their Fig. 10). High westward velocities are found around $160^{\circ} \mathrm{E}$ between 800 and $1400 \mathrm{~m}$ during the months of August and September. Weaker westward anomalies of a few centimeters per second are also expected at $8^{\circ}-10^{\circ} \mathrm{S}$ in August, as more than one meridional Rossby mode could be present (Cravatte et al. 2012). The annual Rossby waves thus explain why stronger than average westward currents along the equator are observed during CASSIOPEE; it may also partly explain the absence of an eastward current at $8.5^{\circ} \mathrm{S}$.

\section{b. Tracer fields properties}

To understand the role of this circulation on the transport of water masses and tracers, sections of oxygen, salinity, and rescaled PV are presented in Figs. 4 and 5. Meridional profiles of zonal velocities and tracer fields are further shown on isopycnal layers chosen to target the cores of the different jets mentioned in section 3a. This complementary diagnostic ensures that the horizontal variations and frontal structures are not the results of local and transient phenomena such as the sudden lifting of isopycnals due to the passage of internal gravity waves.

\section{1) MAIN WATER MASSES}

The different water masses of the southwestern tropical Pacific Ocean are recognizable in Figs. 4 and 5 from the oxygen and salinity distributions. Between the surface and the thermocline (in the upper hundred meters of the three sections), oxygen-rich waters with concentrations above $160 \mu \mathrm{mol} \mathrm{kg}{ }^{-1}$ are characteristic of the saturated mixed layer in equilibrium with the atmosphere (Fig. 4b). Within the thermocline, the central waters display a large range of oxygen content and are more often characterized by a salinity maximum (above $35 \mathrm{psu}$ ), originating from the southeastern subtropics (Kessler 1999). Two major water masses with different signatures in salinity and oxygen are found at intermediate depths: The high oxygen $\left(160 \mu \mathrm{mol} \mathrm{kg}^{-1}\right)$, low salinity (34.3-34.5 psu) modified Antarctic Intermediate Water (AAIW) are located around $1000 \mathrm{~m}$ southward of 
$152.5^{\circ} \mathrm{E}$
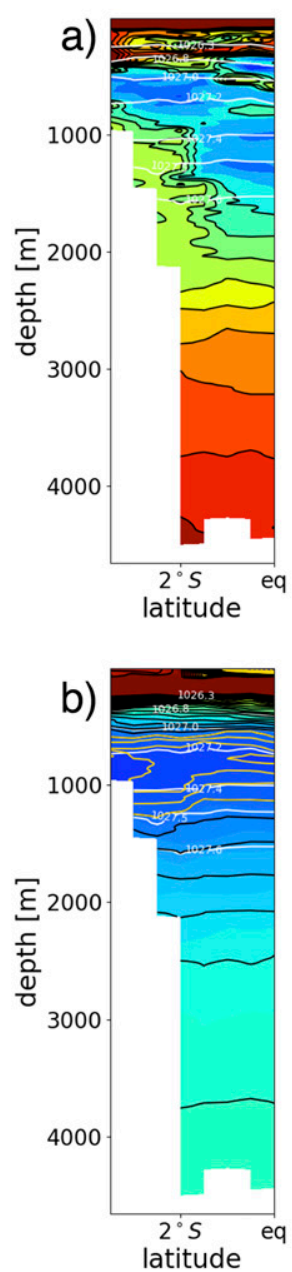

c)

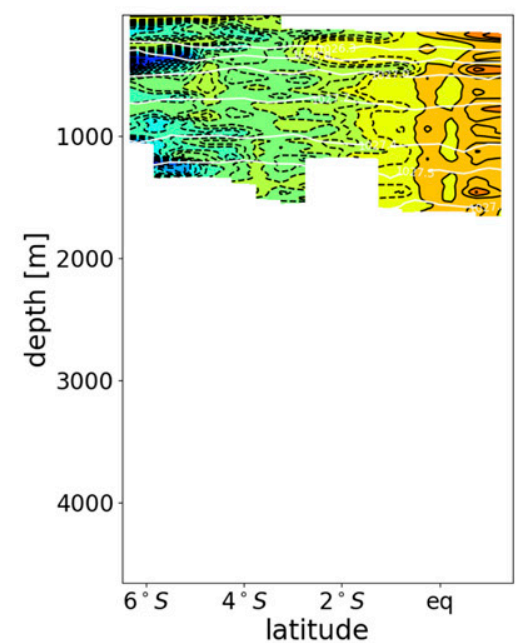

$157.5^{\circ} \mathrm{E}$
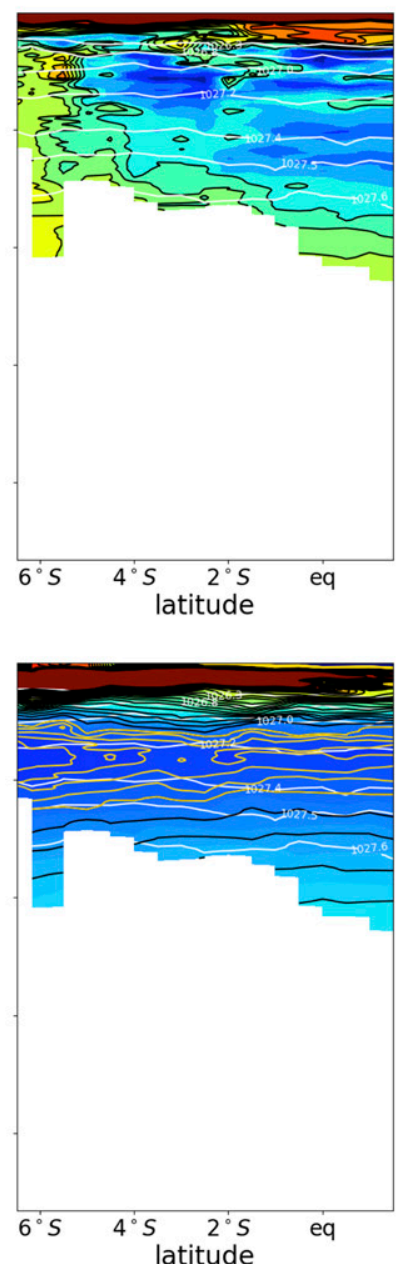

latitude $165^{\circ} \mathrm{E}$
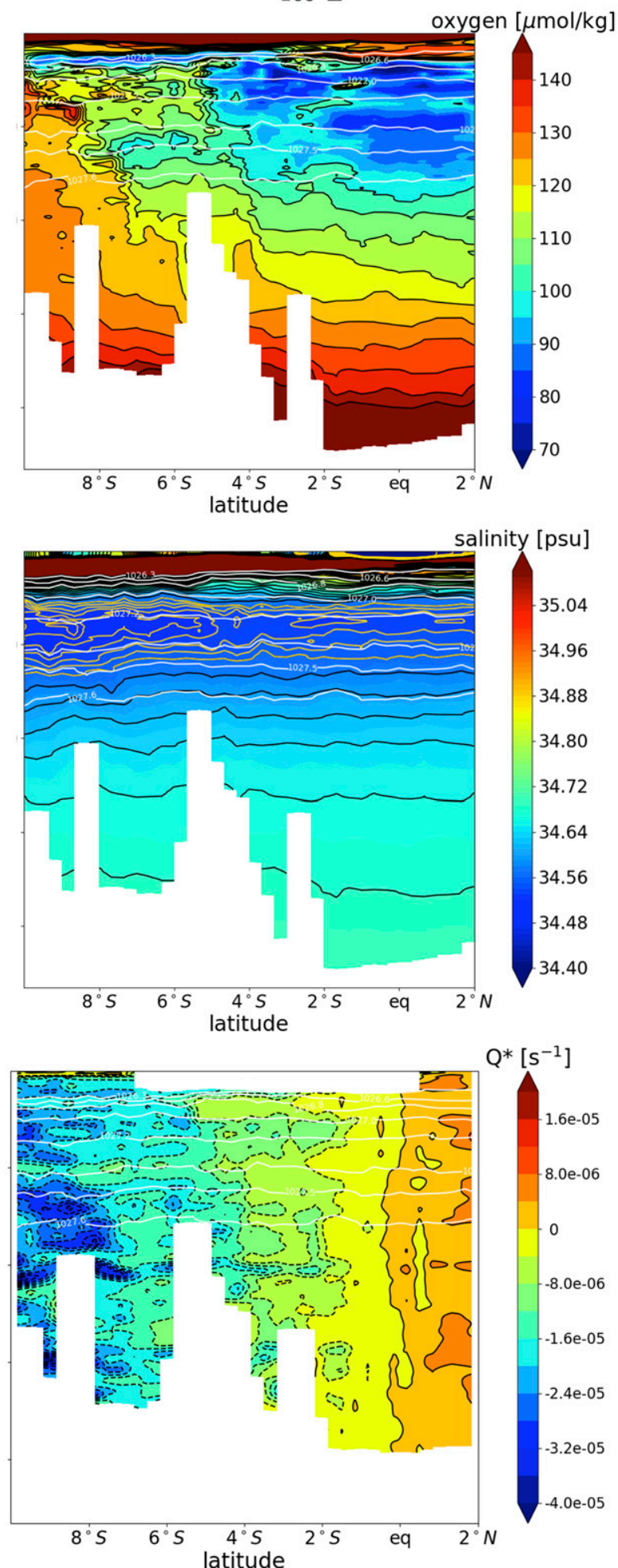

FIG. 5. Tracer sections in CASSIOPEE. (a) Oxygen concentration along the three sections of CASSIOPEE cruise: (left) $152.5^{\circ} \mathrm{E},($ center) $157.5^{\circ} \mathrm{E}$, (right) $165^{\circ} \mathrm{E}$. Contours are every $5 \mu \mathrm{mol} \mathrm{kg}{ }^{-1}$. A vertical Hanning filter over $50 \mathrm{~m}$ has been applied. White lines are density contours. (b) As in (a), but for salinity. Contours are every 0.05 psu. (c) As in (a), but for rescaled potential vorticity (see section 2). Contours are every $0.2 \mathrm{~s}^{-1}$. Note that the $152.5^{\circ} \mathrm{E}$ section could not be computed because it had a too small meridional extension for the computation of derivatives and rescaling. 
$5^{\circ} \mathrm{S}$ (Figs. 5a,b), and the Equatorial Waters (EqW) with oxygen minima and relatively higher salinity content (34.5-34.6 psu) are found between the themocline and $2500 \mathrm{~m}$, between $5^{\circ} \mathrm{S}$ and $5^{\circ} \mathrm{N}$. The mixing region between the AAIW and EqW is found between $15^{\circ}$ and $5^{\circ} \mathrm{S}$ (Bostock et al. 2010), inducing a large-scale smooth meridional gradient of oxygen and salinity. Below $2000 \mathrm{~m}$, the oxygen content increases downward where the very slow northward flow of Antarctic Bottom Water (AABW) and Circumpolar Deep Waters (CDW) brings high oxygen concentrations originating from the Southern Ocean (Fieux and Webster 2017).

\section{2) The equatorial System}

Oxygen-rich waters $\left(140 \mu \mathrm{mol} \mathrm{kg}^{-1}\right)$ are found in the thermocline inside the EUC on the three sections of CASSIOPEE cruise (Figs. 4a,b). These observations confirm that this eastward-flowing current carries oxygen-rich waters from the well-ventilated western boundary toward the less-oxygenated eastern basin (Tsuchiya 1981; Stramma et al. 2010). The oxygen content of the EUC is compatible with the concentrations reported by Stramma et al. (2010). Although they did not sample the same longitudes, they found concentrations of $125 \mu \mathrm{mol} \mathrm{kg}^{-1}$ at $170^{\circ} \mathrm{W}$ (the westernmost section of their paper), decreasing eastward to $30 \mu \mathrm{mol} \mathrm{kg}^{-1}$ at $85^{\circ} \mathrm{W}$.

Between the thermocline and $3000 \mathrm{~m}$, lower concentrations of oxygen $\left(70-90 \mu \mathrm{mol} \mathrm{kg}^{-1}\right)$ are found in the near-equatorial band $2^{\circ} \mathrm{S}-2^{\circ} \mathrm{N}$ (Fig. 5b). The intensity of the oxygen minimum is modulated with depth (as for the velocity, see Fig. 3a). This is very likely the signature of the EDJs. Figure 6 shows the vertical anomalies profile in oxygen concentration and zonal velocity at the equator for the three sections of CASSIOPEE cruise. Original data have been bandpass filtered for vertical scales between 100 and $500 \mathrm{~m}$ to remove small-scale noise and large-scale variations. Both the zonal velocity and oxygen anomalies oscillate with a vertical wavelength of about $330 \mathrm{~m}$, corresponding roughly to the vertical wavelength of the EDJs. These oscillations are especially visible on sections $157.5^{\circ}$ and $152.5^{\circ} \mathrm{E}$, with a clear zonal continuity of vertical minima and maxima, and are intensified in the 500-1800-m layer. Eastward jets (positive zonal velocity anomalies) are associated with positive oxygen concentration anomalies and westward jets (negative zonal velocity anomalies) are associated with negative oxygen concentration anomalies. The magnitude of the oxygen content difference between eastward and westward jets reaches $15-20 \mu \mathrm{mol} \mathrm{kg}^{-1}$ at $500 \mathrm{~m}$ and decreases with depth. While the EDJs signature is still visible in zonal velocity signal below $2000 \mathrm{~m}$, with anomalies of $5 \mathrm{~cm} \mathrm{~s}^{-1}$ on section $152.5^{\circ} \mathrm{E}$, it is nonexistent in the oxygen signal (this will be further discussed in section 5). These results are generally consistent with the findings of Brandt et al. (2012), who show that oxygen concentrations in the equatorial Atlantic are following a large range of variability (up to $60 \mu \mathrm{mol} \mathrm{kg}^{-1}$ ) at a given depth and exhibit oscillations compatible with the 4.5-yr period of the EDJs in this region. To our knowledge, evidence of such a signature in the equatorial Pacific had not been provided yet.

\section{3) THE EXTRAeQuATORIAL LLSCS SYSTEM}

As discussed in the previous section, several meridionally alternating eastward and westward jets are found between the thermocline and $800 \mathrm{~m}$ on the CASSIOPEE sections. The properties of these jets in terms of oxygen, salinity, and PV can be inferred from Fig. 5 and from the vertically averaged tracer variations within isopycnal layers, defined to encompass each individual jet along the $165^{\circ}$ E section (Fig. 7).

Layer 1026.45-1026.7 $\mathrm{kg} \mathrm{m}^{-3}$ (Fig. 7a) encompasses the first Tsuchiya jet. The velocity maximum is found at $2.3^{\circ} \mathrm{S}$ $\left(32 \mathrm{~cm} \mathrm{~s}^{-1}\right)$ and the oxygen maximum $\left(120 \mu \mathrm{mol} \mathrm{kg}^{-1}\right)$ as well, supporting the idea of a transport of oxygen-rich waters by the first Tsuchiya jet. In contrast, PV and salinity both show the presence of a frontal structure at that latitude. Interestingly, a front is also visible in oxygen poleward of the jet, separating off-equatorial waters with high oxygen content from equatorial waters with lower oxygen content. This result is in agreement with Rowe et al. (2000), which also shows a front in PV associated with the first Tsuchiya jet. The relative importance of the arising structure (either as front or maximum) will be discussed with respect to large-scale gradient and physical processes in section 5 .

Layer $1026.8-1027.05 \mathrm{~kg} \mathrm{~m}^{-3}$ (Fig. 7b) is the layer where the core of the second Tsuchiya jet can be found. Its position is detected by maximum positive velocities at $5^{\circ} \mathrm{S}\left(20 \mathrm{~cm} \mathrm{~s}^{-1}\right)$. At the same latitude as zonal velocity maxima, frontal structures are found in the three tracer fields. Oxygen drops from $110 \mu \mathrm{mol} \mathrm{kg}^{-1}$ south of the jet to $90 \mu \mathrm{mol} \mathrm{kg}{ }^{-1}$ north and salinity increases from 34.62 to 34.64 psu. This jet is flanked north and south by westward currents where the tracer fields display very homogeneous values between $9^{\circ}-6^{\circ} \mathrm{S}$ and $4^{\circ}-2^{\circ} \mathrm{S}$.

\section{4) The eXtraequatorial LLICs SYSTEM}

Meridionally alternating eastward and westward zonal jets are also found from below $800 \mathrm{~m}$ to the bottom (section 3a). The striking features on the oxygen sections are the existence of meridional fronts extending over more than $2000 \mathrm{~m}$ (from $500 \mathrm{~m}$ down to $2500-3000 \mathrm{~m}$ ) following the core of eastward jets at $7^{\circ}$ and $4^{\circ} \mathrm{S}$ (Fig. 5a) and at $2^{\circ} \mathrm{S}$ 

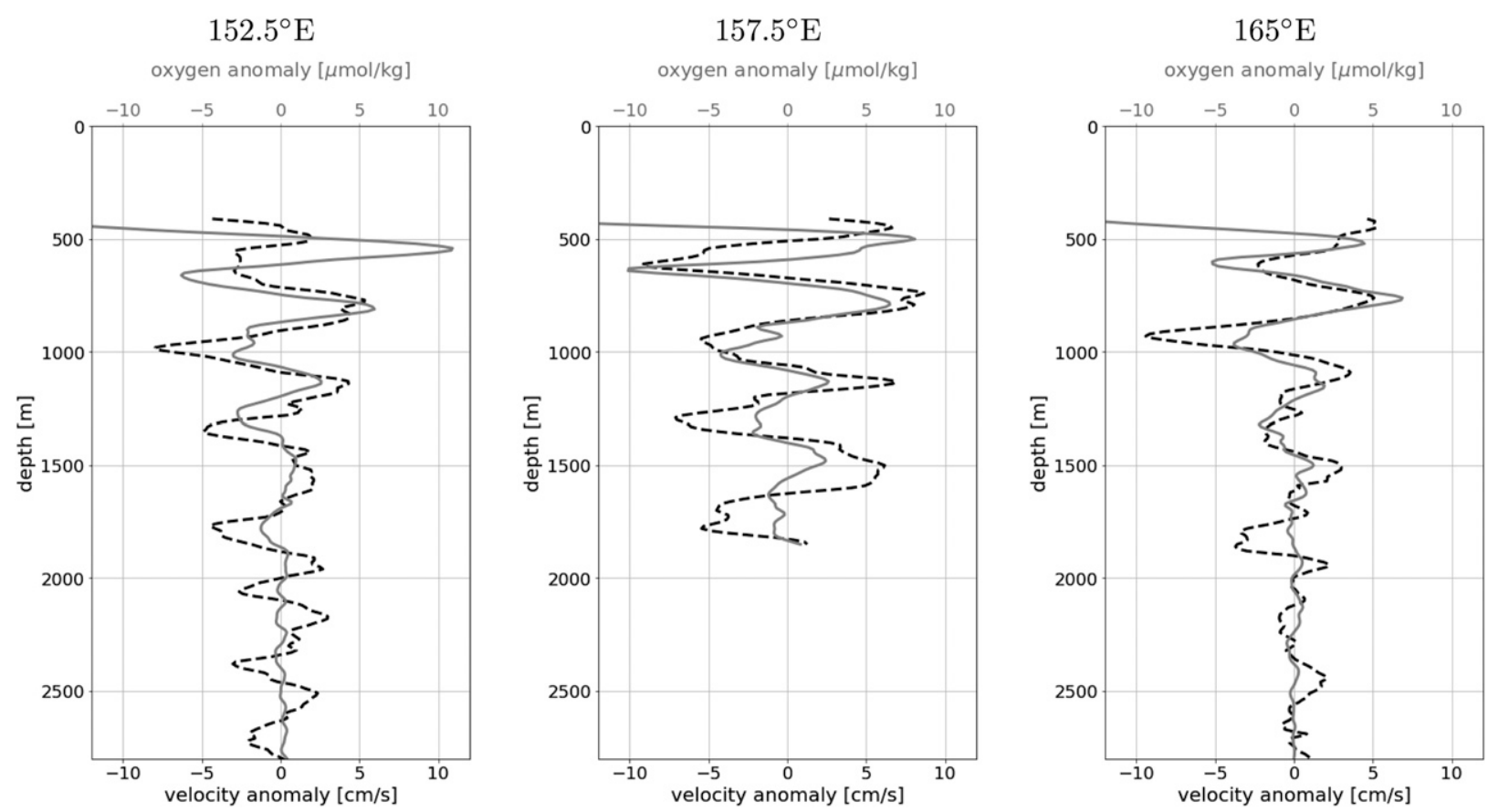

FIG. 6. Signature of EDJs in CASSIOPEE. Vertical zonal velocity (black dashed lines) and oxygen concentration (gray solid lines) anomalies from 300 to $2800 \mathrm{~m}$ averaged between $1^{\circ} \mathrm{N}$ and $1^{\circ} \mathrm{S}$ at longitudes (left) $152.5^{\circ} \mathrm{E}$, (center) $157.5^{\circ} \mathrm{E}$, and (right) $165^{\circ} \mathrm{E}$. Data have been filtered using a 100-500-m bandpass Hanning filter in order to remove the large-scale variation (over $500 \mathrm{~m}$ ) and small scale noise (below $100 \mathrm{~m}$ ).

(Figs. 7c,d) with the same tilt toward the equator with depth as for the currents. Frontal structures are denoted through a convergence of oxygen isopleths alternating with quite homogeneous regions. Here the oxygen values decrease suddenly from 125 to $110 \mu \mathrm{mol} \mathrm{kg}^{-1}$ between $7.5^{\circ}$ and $7^{\circ} \mathrm{S}$, remain around $110 \mu \mathrm{mol} \mathrm{kg}{ }^{-1}$ between $7^{\circ}$ and $4.5^{\circ} \mathrm{S}$ and change again from 110 to $90 \mu \mathrm{mol} \mathrm{kg}^{-1}$ between $4.5^{\circ}$ and $4^{\circ} \mathrm{S}$ (Fig. 5a). Interestingly, these frontal structures are also seen, though they are very weak, in salinity sections in the 800-1000-m depth range corresponding to the core of AAIW salinity minima (Fig. 5b). The quantification of salinity variations appears more clearly in Figs. $7 \mathrm{c}$ and $7 \mathrm{~d}$ : salinity increases of about $0.01 \mathrm{psu}$ at $7^{\circ}$ and $4^{\circ} \mathrm{S}$ and of $0.005 \mathrm{psu}$ at $2^{\circ} \mathrm{S}$. This last value is weak but still significant given the vertical integration of the signal. In between the fronts, salinity presents homogeneous values with latitude. This shows that the core of the salinity minimum coming from the AAIW is gradually eroded from south to north. Last, similar frontal structures are also seen in the PV field. Superimposed on the large-scale PV meridional gradient, one can notice the presence of three frontal structures at $7^{\circ}, 4^{\circ}$, and $2^{\circ} \mathrm{S}$ on section $165^{\circ} \mathrm{E}$ (right panel, Fig. $5 \mathrm{c}$ ) and at $2^{\circ}$ and $4^{\circ} \mathrm{S}$ on section $157.5^{\circ} \mathrm{E}$ (middle panel, Fig. $5 \mathrm{c}$ ).

The corresponding averages in isopycnal layers $1027.2-$ $1027.4 \mathrm{~kg} \mathrm{~m}^{-3}$ and $1027.49-1027.57 \mathrm{~kg} \mathrm{~m}^{-3}$ are shown in Figs. $7 \mathrm{c}$ and $7 \mathrm{~d}$. Note that because the LLICs are slanted with depth (Fig. 3a), two different isopycnal layers are needed to describe their depth dependence. Figures $7 \mathrm{c}$ and $7 \mathrm{~d}$ show the very good correlation between oxygen, salinity, and PV. The three tracers present staircase meridional variations (alternation of frontal and homogeneous regions) with fronts coinciding with eastward jets cores and homogeneous regions with westward jets. As shown on the different sections (Fig. 5), these structures remain zonally coherent as they are present on the three sections with similar amplitudes.

The CASSIOPEE cruise helped to determine the tracer field structures associated with zonal jets, due to the high resolution of the cruise stations and the good quality of the full-depth L-ADCP data. It highlighted in particular unexpected frontal structures collocated for all tracer fields studied (oxygen, salinity, and PV) in all eastward jets except for the oxygen in the EUC, Tsuchiya jets, and EDJs, where local maxima are found.

\section{Temporal and zonal coherence across the basin}

The purpose of this section is to determine to what extent the tracer structures associated with the middepth zonal jets during the CASSIOPEE cruise resemble those 

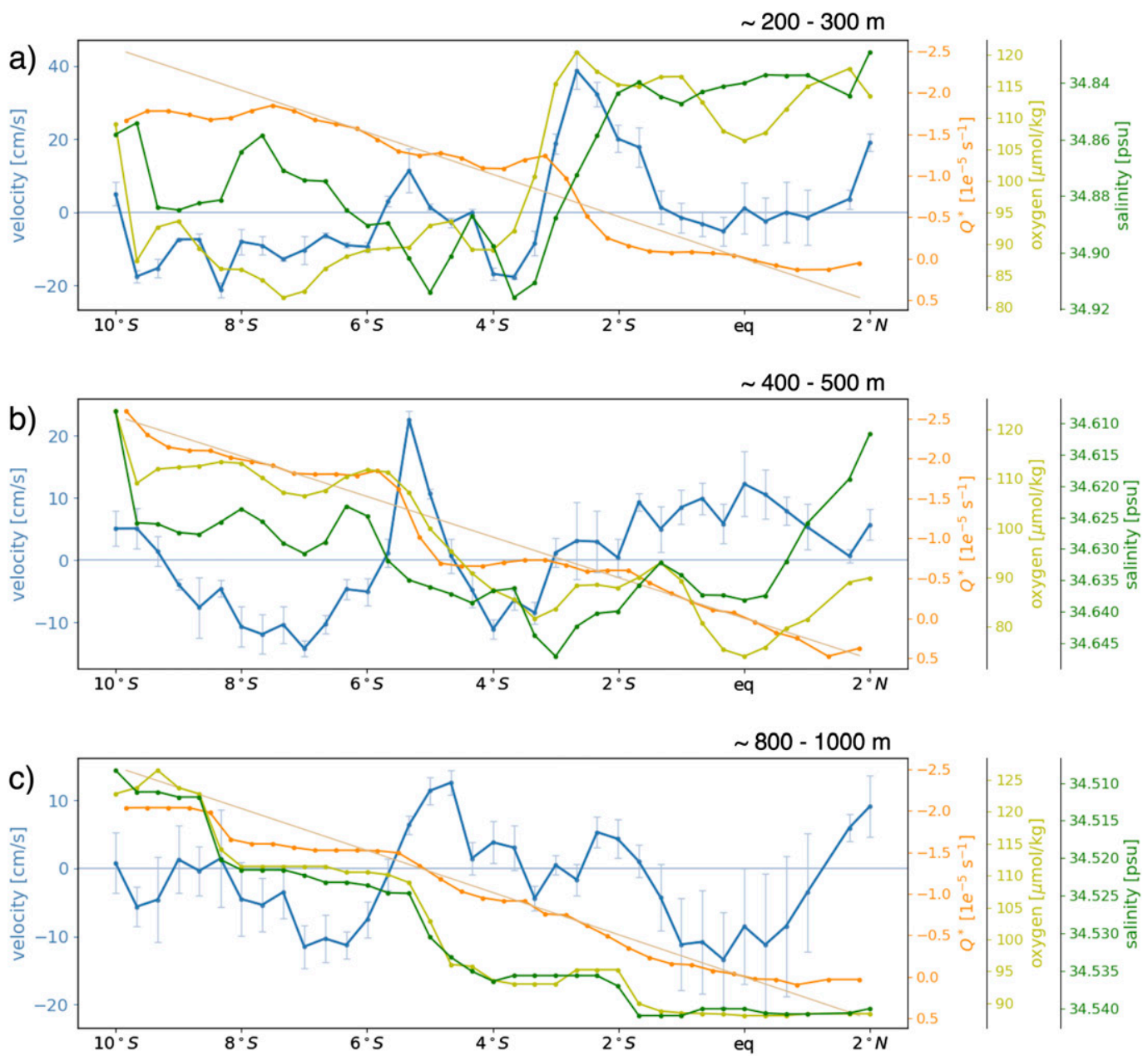

$\sim 1500-1800 \mathrm{~m}$

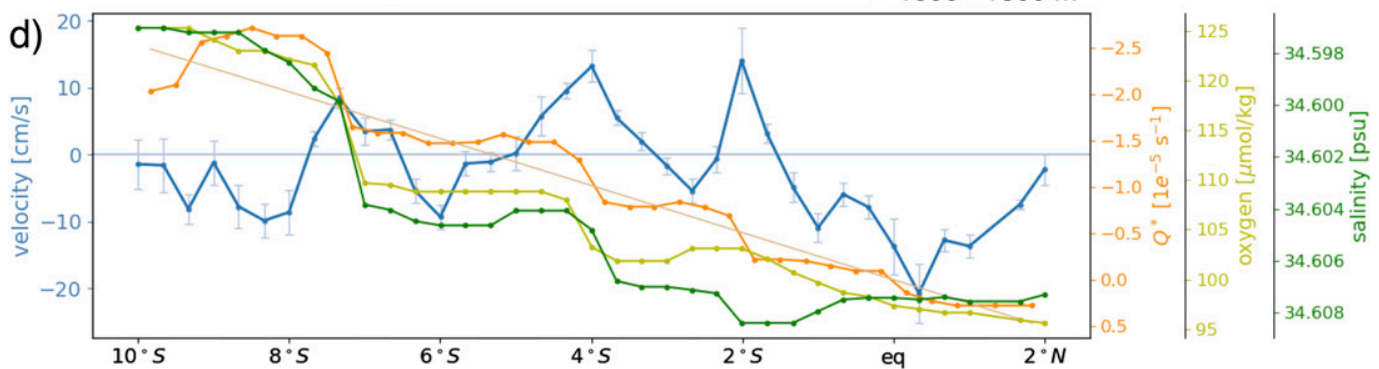

FIG. 7. Meridional profiles of zonal jets and tracers averaged over isopycnal layers for the $165^{\circ} \mathrm{E}$ section of the CASSIOPEE cruise: L-ADCP zonal velocity (blue), oxygen (pale green), salinity (dark green), and rescaled potential vorticity (orange) computed as described in section 2 . The blue error bars indicate the standard deviation of the velocity within the isopycnal layer. The different layers are chosen to target the different jets observed: (a) First Tsuchiya jet $\left(1026.38-1026.67 \mathrm{~kg} \mathrm{~m}^{-3}\right)$, (b) second Tsuchiya jet $\left(1026.8-1027.05 \mathrm{~kg} \mathrm{~m}^{-3}\right.$ ), (c) upper LLIC system $\left(1027.2-1027.4 \mathrm{~kg} \mathrm{~m}^{-3}\right)$, and (d) lower LLIC system $\left(1027.49-1027.63 \mathrm{~kg} \mathrm{~m}^{-3}\right)$. Note that for the sake of clarity, potential vorticity and salinity axes are decreasing.

in the rest of the basin at different periods. For this purpose, we compared the results of the previous section with meridional profiles of oxygen and salinity in isopycnal layers taken from historical cruises in the whole basin (see section 2). Ten meridional sections were considered: $165^{\circ} \mathrm{E}(\mathrm{P} 13), 180^{\circ}(\mathrm{P} 14), 170^{\circ} \mathrm{W}(\mathrm{P} 15), 155^{\circ} \mathrm{W}, 150^{\circ} \mathrm{W}$ (P16), $140^{\circ} \mathrm{W}, 135^{\circ} \mathrm{W}(\mathrm{P} 17), 125^{\circ} \mathrm{W}, 110^{\circ} \mathrm{W}$ (P18), and $95^{\circ} \mathrm{W}$. The location and details about each cruise are given 

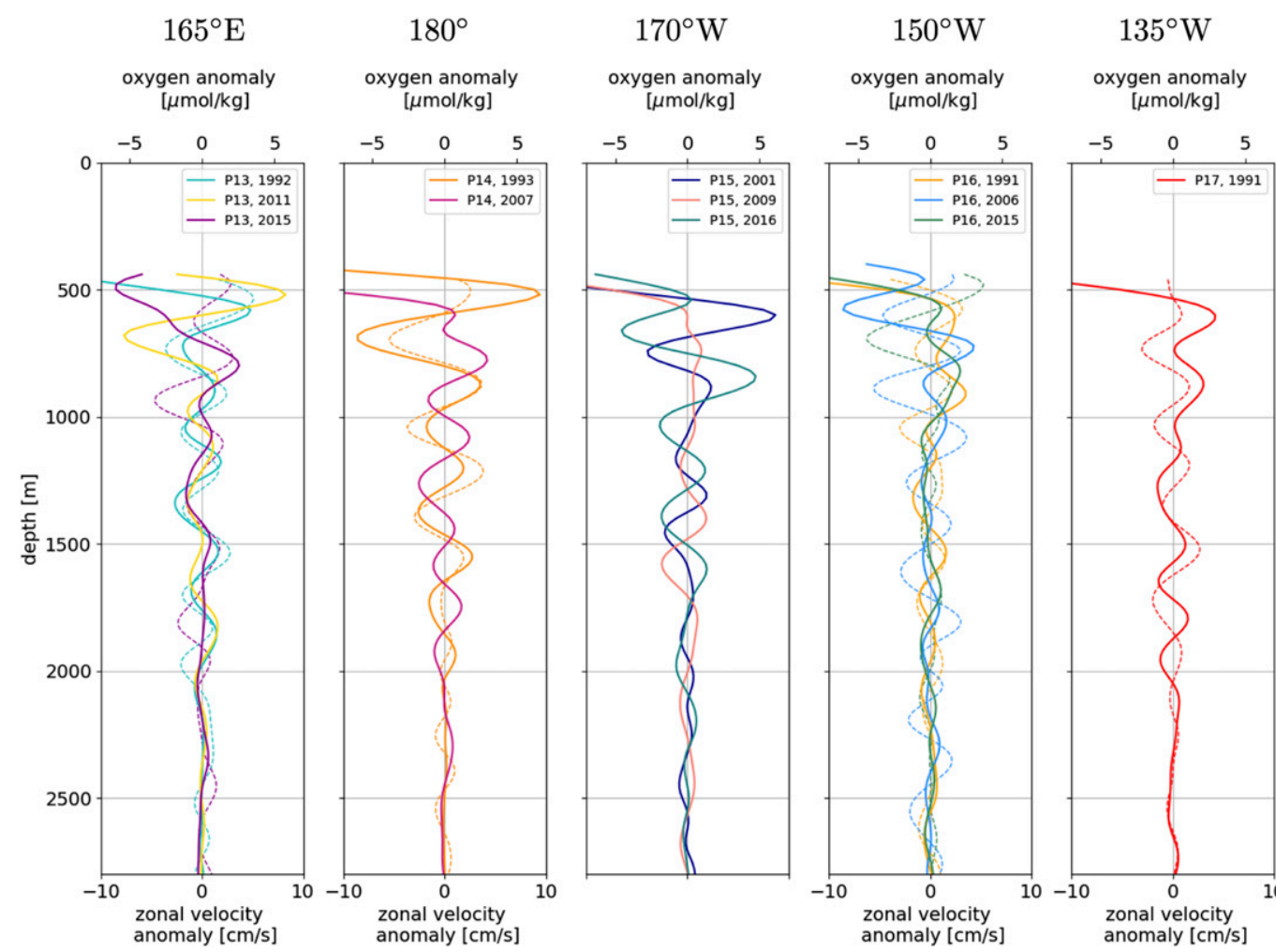

$110^{\circ} \mathrm{W}$

FIG. 8. Oxygen profiles in EDJs. Equatorial profiles of zonal velocity anomaly (colored dashed lines) and oxygen concentration anomaly (colored solid lines) at the different WOCE locations (Fig. 2). Anomalies have been computed using a 100-500-m bandpass filter. From left to right: P13 $\left(165^{\circ} \mathrm{E}\right), \mathrm{P} 14\left(180^{\circ}\right) \mathrm{P} 15\left(170^{\circ} \mathrm{W}\right), \mathrm{P} 16\left(150^{\circ} \mathrm{W}\right), \mathrm{P} 17\left(135^{\circ} \mathrm{W}\right)$, and $\mathrm{P} 18\left(110^{\circ} \mathrm{W}\right)$.

in Tables 2 and 3 and Fig. 2. For each of them we used S-ADCP or L-ADCP measurements, when available.

\section{a. The EDJ system}

As for the CASSIOPEE cruise, vertically alternating anomalies in oxygen do exist above $1800 \mathrm{~m}$ at the equator and may be related to the presence of the EDJ system (Fig. 8). The anomalies are much weaker below. They are of similar amplitude for the P13 and P15 cruises, west of the date line, and decrease eastward of the date line. They are found to be highly variable: the depths of the oxygen extrema vary from one cruise to another, though the vertical scale remains similar. For example, at $170^{\circ} \mathrm{W}$ (P15), we observe a phase reversal between the 2009 and 2016 cruises oxygen signal in the depth range $1000-1800 \mathrm{~m}$. This is consistent with the vertically propagating characteristics of the EDJs. Given the approximate 12-yr period, we do not expect signals from different snapshot cruises to coincide but to have different phases, as noted by Brandt et al. (2012) in the Atlantic. However, a single period of 12 years is hardly identifiable from Fig. 8. For example, cruises P14, 1993 and P14, 2007 are recorded 14 years apart, and still the signals present a phase opposition, which seems not consistent with a 12-yr period. Moreover, the phase lag between different signals are not depth independent. This rather suggests that EDJs have a broadband vertical scale and phase propagation period.

\section{b. The LLSCs system (including the Tsuchiya jets) and upper SICC and NICC}

The characteristic densities of the LLSC jets cores strongly depend on latitude and longitude: the cores of the multiple eastward LLSC jets are known to get denser as the thermocline deepens poleward (Cravatte et al. 2017), while the cores of the first and second SSCC are observed to get lighter as the thermocline shoals from west to east (Rowe et al. 2000). To take into account these variations of density, we define isopycnal layers with respect to the jets' position (Table 4).

Between $10^{\circ} \mathrm{S}$ and $10^{\circ} \mathrm{N}$, the Tsuchiya jets are discernible with positive velocities around $20 \mathrm{~cm} \mathrm{~s}^{-1}$ at all longitudes (Fig. 9). The NSCC and SSCC are found to shift poleward from $3^{\circ} \mathrm{N}$ and $3^{\circ} \mathrm{S}$ (respectively) in the western part of the basin $\left(170^{\circ} \mathrm{W}\right)$ to $5^{\circ} \mathrm{N}$ and $5^{\circ} \mathrm{S}$ in the eastern part $\left(110^{\circ} \mathrm{W}\right)$ in agreement with Rowe et al. (2000). They are associated with oxygen maxima (Fig. 9a) whose amplitudes remain quite constant until 
TABLE 4. Density layers used to target the first and second Tsuchiya jets in Fig. 9 and the SICC and NICC in Fig. 10.

\begin{tabular}{|c|c|c|c|}
\hline Longitude & Density layer & Longitude & Density layer \\
\hline $170^{\circ} \mathrm{W}$ & $1026.4-1026.8 \mathrm{~kg} \mathrm{~m}^{-3}$ & \multirow{6}{*}{ All } & \multirow{7}{*}{$1027.15-1027.25 \mathrm{~kg} \mathrm{~m}^{-3}$} \\
\hline $155^{\circ} \mathrm{W}$ & $1026.4-1026.8 \mathrm{~kg} \mathrm{~m}^{-3}$ & & \\
\hline $140^{\circ} \mathrm{W}$ & $1026.3-1026.7 \mathrm{~kg} \mathrm{~m}^{-3}$ & & \\
\hline $125^{\circ} \mathrm{W}$ & $1026.3-1026.6 \mathrm{~kg} \mathrm{~m}^{-3}$ & & \\
\hline $110^{\circ} \mathrm{W}$ & $1026.2-1026.6 \mathrm{~kg} \mathrm{~m}^{-3}$ & & \\
\hline $95^{\circ} \mathrm{W}$ & $1026.2-1026.4 \mathrm{~kg} \mathrm{~m}^{-3}$ & & \\
\hline \multicolumn{2}{|c|}{ Fig. 9} & Fig. 10 & \\
\hline
\end{tabular}

$140^{\circ} \mathrm{W}$ (corresponding to a local anomaly of $50 \mu \mathrm{mol} \mathrm{kg}^{-1}$ ) and decrease eastward (about $20 \mu \mathrm{mol} \mathrm{kg}^{-1}$ at $110^{\circ} \mathrm{W}$ ). The maximum is no longer discernible at $95^{\circ} \mathrm{W}$. The oxygen content is however stronger in the NSCC than in the SSCC in the middle of the basin and can be variable from one cruise to another (for instance, at $125^{\circ} \mathrm{W}$ oxygen content in the northern Tsuchiya jet varies from $80 \mu \mathrm{mol} \mathrm{kg}^{-1}$ for GP-106 to $30 \mu \mathrm{mol} \mathrm{kg}^{-1}$ in GP-504). Note that the erosion of maxima in the Tsuchiya jets along their path to the eastern boundary shows that not only advection but also other processes such as consumption, diffusion or mixing are taking place (see section 5). This is in agreement with the findings of Stramma et al. (2010), who analyzed cross-equatorial oxygen sections and found oxygen content of $60 \mu \mathrm{mol} \mathrm{kg}-1$ at $140^{\circ} \mathrm{W}$, decreasing eastward to about $30 \mu \mathrm{mol} \mathrm{kg}^{-1}$ at $95^{\circ} \mathrm{W}$. The signature in salinity of these Tsuchiya jets is quite different. The most noticeable feature is the presence of a front within the northern Tsuchiya jet, visible at each longitude, where the salinity decreases from 34.8 psu equatorward to 34.65 psu poleward of the front (Fig. 9b). This front is flanked by homogeneous or slowly varying regions and indicates the presence of a barrier to mixing between northern and southern water masses. The salinity signature associated with the SSCC and sSSCC is either too weak with respect to the precision of the measurements or not zonally coherent.

Deeper, the layer $1027.15-1027.25 \mathrm{~kg} \mathrm{~m}^{-3}$ encompasses the off-equatorial LLSC and the upper NICC and SICC (Fig. 10 and Table 4). The NICC and SICC are found at $2^{\circ}$ on each side of the equator. They are especially visible in longitudes $160^{\circ}-170^{\circ} \mathrm{E}$ in Argo geostrophic velocities (black curve in Fig. 10) and are measured by ADCP data throughout the basin. These jets coincide with oxygen maxima with relative amplitude of about $20 \mu \mathrm{mol} \mathrm{kg}{ }^{-1}$. Farther off-equator, small-scale features that can be related to the jets' structures do exist and are superimposed on the large-scale meridional variation of oxygen in this region. However, the observed profiles are very noisy and no zonally coherent signal emerges. The jets themselves are relatively weak $\left(1-3 \mathrm{~cm} \mathrm{~s}^{-1}\right)$ and their position is subject to a strong variability, which may drastically complicate the picture of tracer structures on a single snapshot.

\section{c. The extraequatorial LLICs system}

To evaluate the zonal and temporal coherence of LLICs structures throughout the tropical Pacific basin, we plot all the meridional profiles on a single graph together with the CR17 mean zonal velocity (section 2c) for the isopycnal layer $1027.4-1027.6 \mathrm{~kg} \mathrm{~m}^{-3}$ corresponding approximately to the 1000-1400-m depth range (Fig. 11).

First, staircase profiles in oxygen and salinity are observed from $20^{\circ} \mathrm{S}$ to $10^{\circ} \mathrm{N}$ for all cruises at these depths, with fronts of amplitude 15-20 $\mu \mathrm{mol} \mathrm{kg}^{-1}$ (oxygen) and $0.005-0.01$ psu (salinity) alternating with homogeneous regions extending over about $2^{\circ}$ of latitude. Second, staircase profiles are very coherent from one cruise to another (independently of the longitude, year, and period of the year at which the data were recorded). Indeed, a front in oxygen is, for example, found at $5^{\circ} \mathrm{N}$ at $110^{\circ} \mathrm{W}$ during the cruises $\mathrm{P} 18,1994$ and $\mathrm{P} 18,2016$ carried out 22 years apart. This front was also found at $135^{\circ} \mathrm{W}$ in 1991 and at $150^{\circ} \mathrm{W}$ in 2015 and 1991 . Another front is found at $8^{\circ} \mathrm{N}$ during the same cruises. P13, 2011 and P15, 2001 both capture frontal structures in oxygen and salinity at $1.5^{\circ} \mathrm{S}$ and $4^{\circ}$ corresponding to the position of the SICC and the second intermediate eastward jet (Figs. 11a-c). Similarly, frontal structures in oxygen and salinity profiles are observed at $11^{\circ}, 14^{\circ}$ and $17^{\circ} \mathrm{S}$ in 2001 and 2009 at $170^{\circ} \mathrm{W}$ at the position of eastward currents. Note that at these depths, unlike in the upper layers where they are associated with maxima, the SICC and NICC are associated with frontal structures. The meridional distance between frontal structures is close to $3^{\circ}$ in latitude, corresponding to the meridional scale of the meridionally alternating zonal jets. To highlight this relation, normalized spectrum of the climatological Argo geostrophic velocity and tracer profiles in the same isopycnal layer are plotted against the meridional wavenumber (Figs. 11d,e). Maximum power density is found at a meridional wavenumber $k_{y} \simeq 0.33$, corresponding to a meridional wavelength of $\lambda_{y} \simeq 3^{\circ}$. 


\section{$170^{\circ} \mathrm{W}$}

$155^{\circ} \mathrm{W}$

$140^{\circ} \mathrm{W}$

$125^{\circ} \mathrm{W}$

$110^{\circ} \mathrm{W}$

$95^{\circ} \mathrm{W}$

a) $\underset{50}{\operatorname{Oxygen}[u \mathrm{~mol} / \mathrm{kg}]}]_{100}$

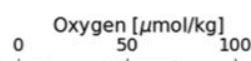

$0 \quad \underset{50}{0}[\mu \mathrm{mol} / \mathrm{kg}]{ }_{100}$

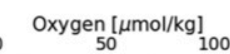

$0 \quad \underset{50}{O}{ }_{100} \quad 0 \quad \underset{50}{\text { Oxygen }[\mu \mathrm{mol} / \mathrm{kg}]}{ }_{100}$
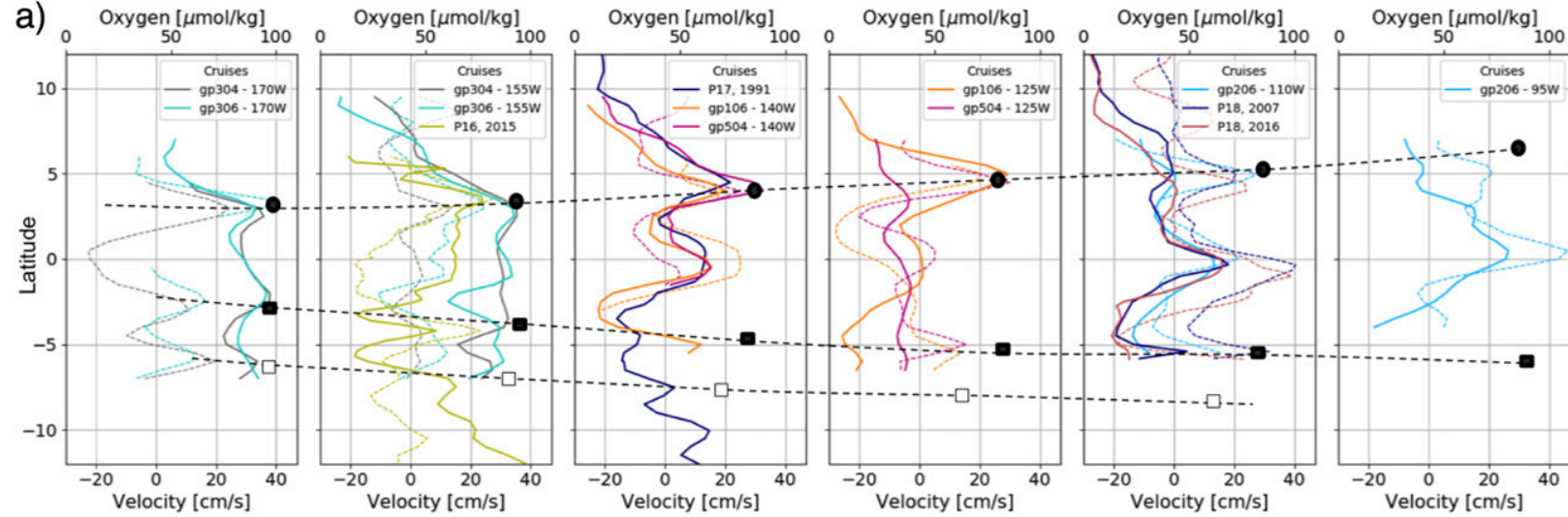

${ }_{50}$ Oxygen $[\mu \mathrm{mol} / \mathrm{kg}]{ }_{100}$

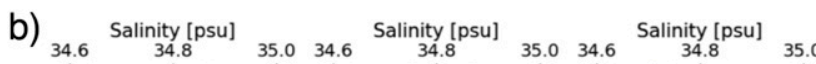
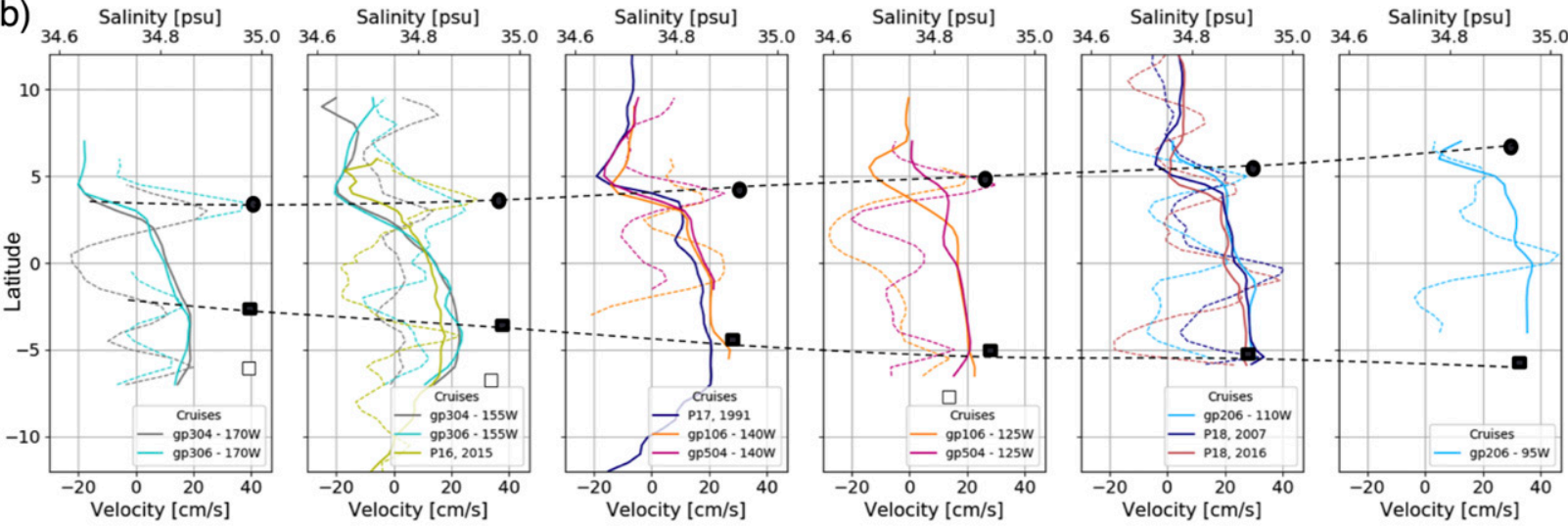

$35.0 \quad 34.6 \quad \begin{gathered}\text { Salinity [p } \\ 34.8\end{gathered}$

- NSCC (northern Tsuchiya jet)

positions from

Rowe et al. (2000)

- SSCC (southern Tsuchiya jet)

$\square$ Secondary SSCC

FIG. 9. Zonal evolution of tracers profiles in first and second Tsuchiya jets. TAO and WOCE sections averaged over isopycnal layers described in Table 4 for (top) oxygen and (bottom) salinity. Colored dashed lines represent velocity and solid lines represent tracers. Symbols represent the positions of the northern and first and second southern Tsuchiya jets previously reported by Rowe et al. (2000). Black dashed lines connect the jet cores positions.

These observations confirm that while oxygen maxima are associated with the near-equatorial components of the zonal jet systems (EUC, Tsuchiya jets, EDJs), staircase profiles are a general and permanent tracer structure associated with extraequatorial and relatively deep (deeper than $1000 \mathrm{~m}$ ) zonal jets in the tropical Pacific ocean (LLICs). They show the spatial coincidence of all tracer variations as staircase profiles, which consist in fronts inside eastward currents and homogeneous properties inside westward currents.

\section{Discussion}

The aim of this section is to discuss the following points: (i) What do the observed tracer structures tell us about the dynamics of the zonal jets? Which process is able to homogenize tracers at very specific locations and to create fronts in between, such as those observed in the core of the eastward zonal LLICS jets? (ii) What is the effect of the zonal circulation on the water mass distribution and on the ventilation of the equatorial Pacific?

\section{a. Do staircase profiles result from isopycnic mixing?}

We discuss here isopycnic processes associated with zonal jets that may explain the observed tracer structures: (i) zonal advection and (ii) turbulent diffusion (Figs. 13a-c). Zonal advection can clearly explain the presence of minima and maxima observed in the core of some jets (section $4 \mathrm{~b}$ ). However, the generation of observed staircase profiles requires more complex dynamics than the two aforementioned processes. Indeed, zonal advection can generate sharp fronts by straining a 
$160-170^{\circ} \mathrm{E}$

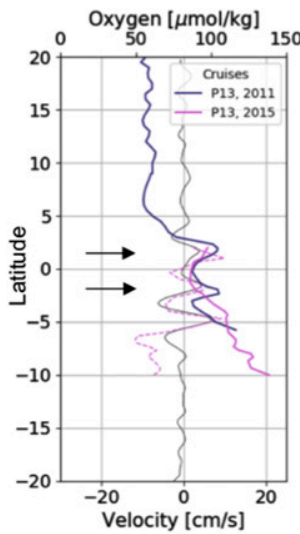

$165-175^{\circ} \mathrm{W}$

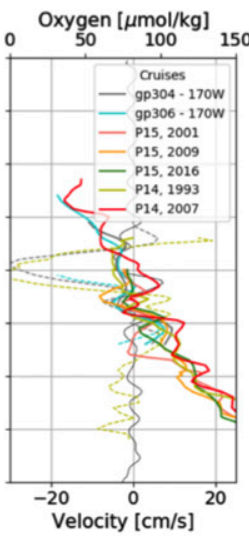

$145-155^{\circ} \mathrm{W}$

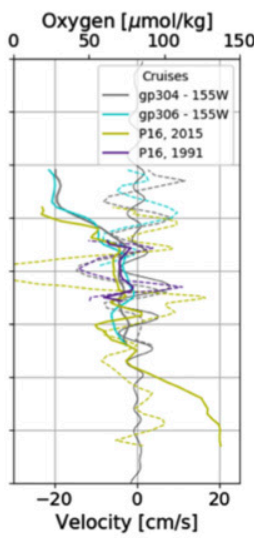

$135-145^{\circ} \mathrm{W}$

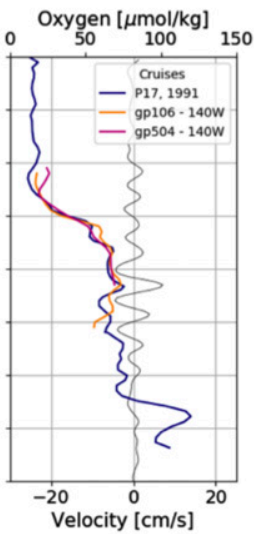

$120-130^{\circ} \mathrm{W}$

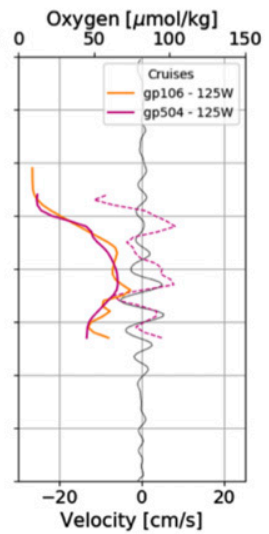

$105-115^{\circ} \mathrm{W}$

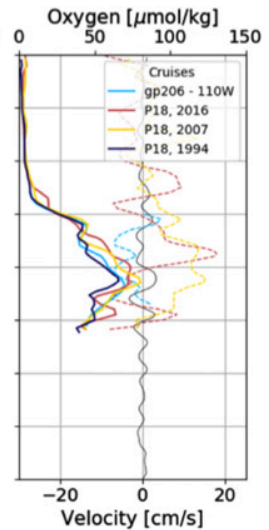

$\longrightarrow$ SICC / NICC positions

FIG. 10. Zonal evolution of tracers profiles in LLSC system. Meridional cruise sections at different longitudes across the tropical Pacific Ocean for (top) oxygen and (bottom) salinity. From left to right: $160^{\circ}-170^{\circ} \mathrm{E}, 165^{\circ}-175^{\circ} \mathrm{W}, 145^{\circ}-155^{\circ} \mathrm{W}, 135^{\circ}-145^{\circ} \mathrm{W}, 120^{\circ}-130^{\circ} \mathrm{W}$, and $105^{\circ}-115^{\circ} \mathrm{W}$. Colored dashed and solid lines represent velocity and tracers associated with each cruise. Solid gray lines represent the mean geostrophic velocity from CR17 product averaged in the same longitude boxes. All data are averaged within the isopycnal layer $1027.15-1027.25 \mathrm{~kg} \mathrm{~m}^{-3}$ (Table 4). The eastward jets on each side of the equator, indicated by black arrows on the left panel are the SICC and NICC.

property gradient field, but in this case the sharpened property gradients would coincide with the maximum velocity shear, that is, in between the jets. Thus, zonal advection, even in a slanting gradient (Fig. 13b), cannot explain the location of frontal regions inside jets. In addition, it cannot explain the regions of homogeneous property. Similar inconsistencies are found for the diffusion and homogenization of tracers in closed gyres, as discussed by Rhines and Young (1982) for PV. Closed gyres determine regions where tracers are confined and can be homogenized by horizontal diffusion. The possibility that tropical middepth zonal jets may form recirculation gyres has been discussed by Rowe et al. (2000) and Ascani et al. (2010). However this mechanism would result in uniform tracer regions localized within pairs of eastward and westward jets forming a gyre (Fig. 13c) and not within westward jets as observed. Thus, even if zonal advection and diffusion associated with zonal jets play a role in the transport of tracers, these processes alone cannot explain the observations.

Alternatively, staircase profiles might be explained by the existence of meridionally inhomogeneous isopycnic mixing, creating regions of uniform tracers flanked by regions of increased tracer gradient (as described in Fig. 13d). In our case, mixing would be enhanced within westward jets and inhibited within eastward jets, at the location of the fronts. The existence of such inhomogeneous isopycnic mixing is not unrealistic: it is consistent with theoretical studies and idealized numerical simulations of geophysical flows on a beta plane that explain how zonal jets can be maintained against dissipation.
The principle is that if zonal jets do exist, they will necessarily be associated to PV variations. Isopycnal mixing will then be enhanced in regions where the PV gradient is weak and inhibited in regions where the PV gradient is strong (PV front), resulting in an inhomogeneous mixing and eventually the formation of staircases (McIntyre 1982; Baldwin et al. 2007; Dritschel and McIntyre 2008; Berloff et al. 2009; Dritschel and Scott 2011). It is important to note that such processes do not explain the generation of the zonal jets, but only their equilibration. Even though our analysis is not exhaustive, the similarity between all tracers profiles and the consistency of the frontal and homogeneous regions with the location of observed zonal jets (sections 3 and 4) suggest that the localized mixing mechanism could be at the origin of the observed staircase profiles.

In addition, staircase structures remain coherent over a large part of the basin and over a period of at least 20 years (Fig. 11), supporting the idea that an equilibrium is reached between the processes at play. In particular, in the presence of a large-scale zonal gradient of properties, zonal advection by jets will create advective tracer anomalies (Fig. 13a), that have to be equilibrated by other processes. Additional mechanisms are possible. For example, the modification of large-scale vertical mixing by the vertical shear of the strongest jets may impact the tracers' distribution. The structuration of ecosystems by the jet dynamics could lead, in the case of the oxygen, to localized increased consumption regions, also modifying the meridional structure of oxygen. Increased concentrations of marine snow at the equator, 

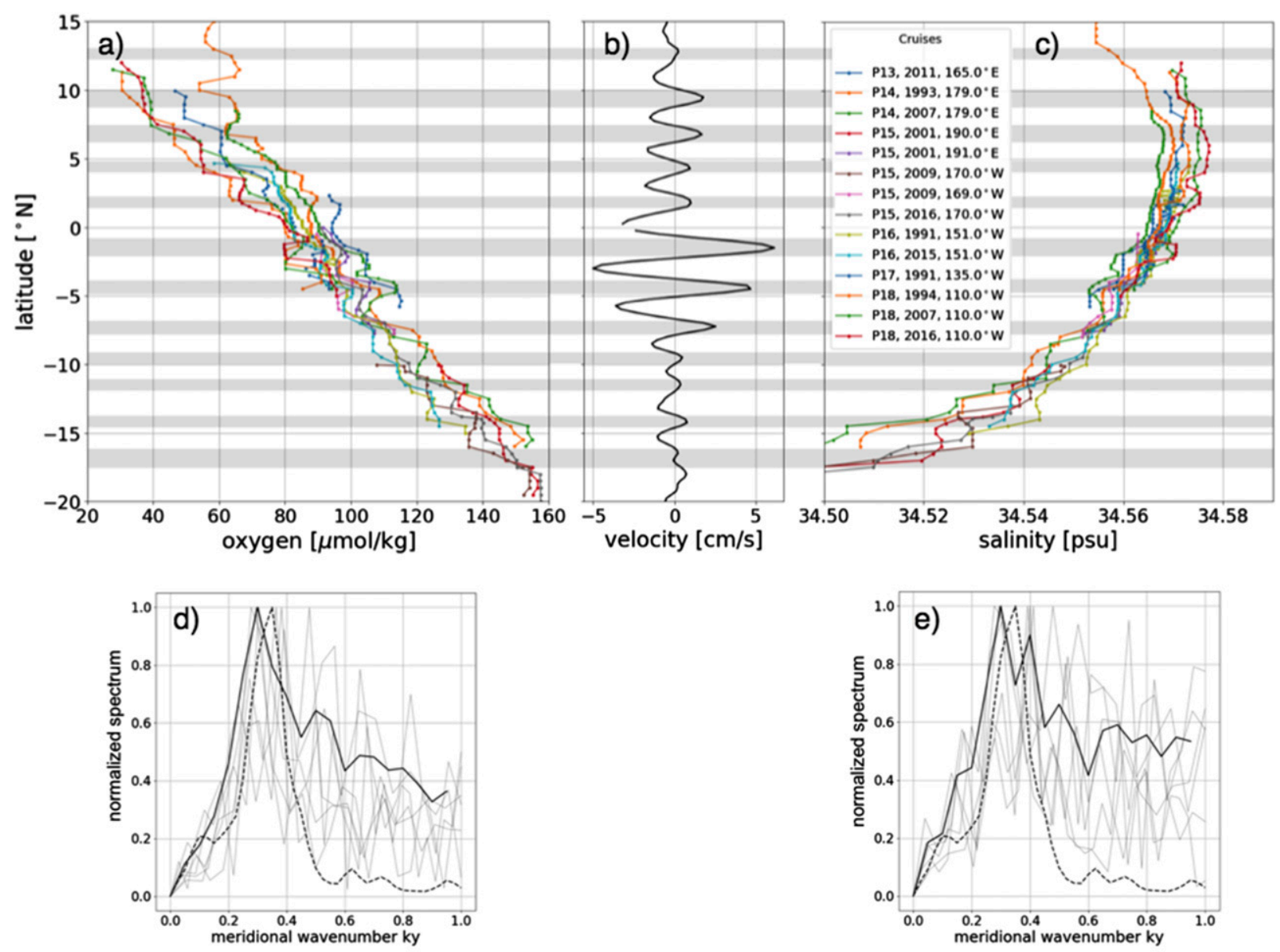

[cycle per degree]

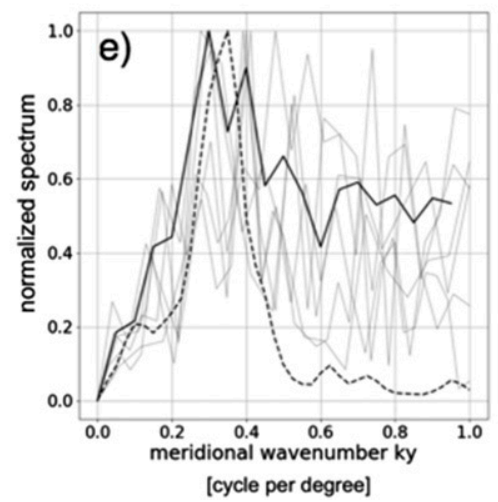

FIG. 11. Tracers profiles in LLIC system. (top) Profiles of all WOCE cruises (Fig. 2 and Table 2) averaged in the isopycnic layer 1027.4$1027.5 \mathrm{~kg} \mathrm{~m}^{-3}$ and filtered using a meridional filter of $1.5^{\circ}$ of the different properties: (a) oxygen, (b) zonal velocity from CR17 averaged from $165^{\circ} \mathrm{E}$ and $110^{\circ} \mathrm{W}$, and (c) salinity. Shaded regions in the background color indicate the location of eastward jets. (bottom) Normalized meridional spectrum associated with these data. Thick dashed line: spectrum of the velocity (as described above), light gray lines: spectrum of each individual cruise tracer profile for (d) oxygen and (e) salinity, and solid black line: mean of all individual cruises spectra.

between middepth eastward jets (the SICC and the NICC), has indeed been reported recently (Kiko et al. 2017). Finally, the mechanisms associated with the generation of the jets (see Ménesguen et al. 2019, and references therein) could also act on tracers. A full understanding of the relative contributions of all these terms to maintain the staircase structures would require a dedicated modeling study and is beyond the scope of this paper.

\section{b. What are the implications for the transport of water masses and the ventilation of the deep ocean?}

To better understand how waters may be transported or modified at basin scale by the systems of zonal jets, we need to examine the water masses present and their large-scale gradients.
The equatorial basin is filled from the thermocline to $2500 \mathrm{~m}$ and between $5^{\circ} \mathrm{S}$ and $5^{\circ} \mathrm{N}$ by the $\mathrm{EqW}$, with horizontal homogeneous temperature and salinity properties (Fieux and Webster 2017). Therefore, the salinity background gradient is primarily meridional and concentrated at and poleward of the EqW boundary (Figs. 12b-d). It is thus not surprising that advective anomalies within zonal jets do not show up for salinity but that staircases are present for the Tsuchiya jets and the LLICs (Figs. 5, 9b, and 11). Local homogenization processes, which gradually lead to the transformation of the off-equatorial water masses to the equatorial water mass, might then play an important role in the erosion of intermediate water masses in the tropics.

Unlike salinity, oxygen concentrations present strong contrasts at basin-scale in the tropical Pacific, due to the 
a)

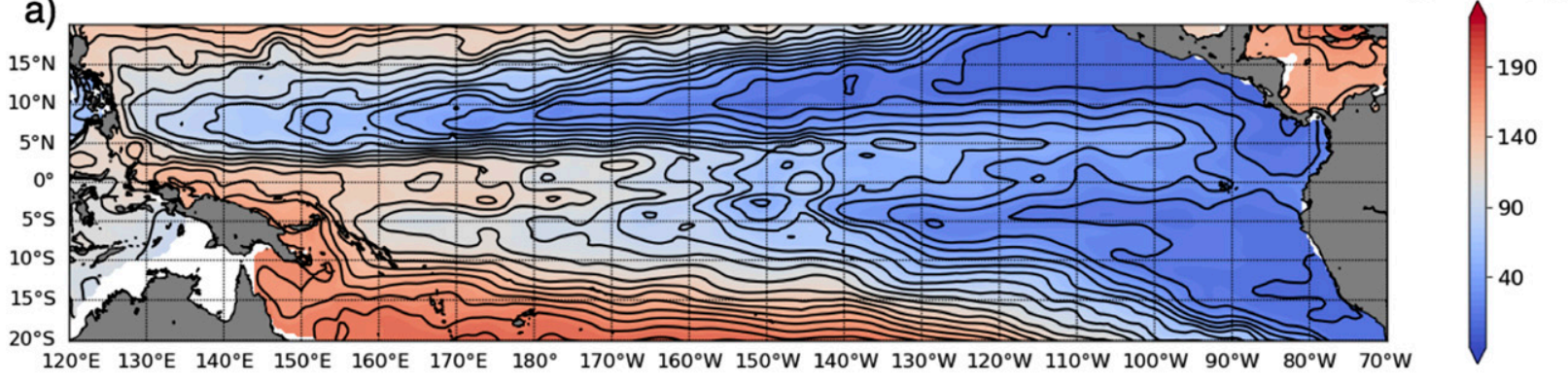

oxygen [umol/kg]
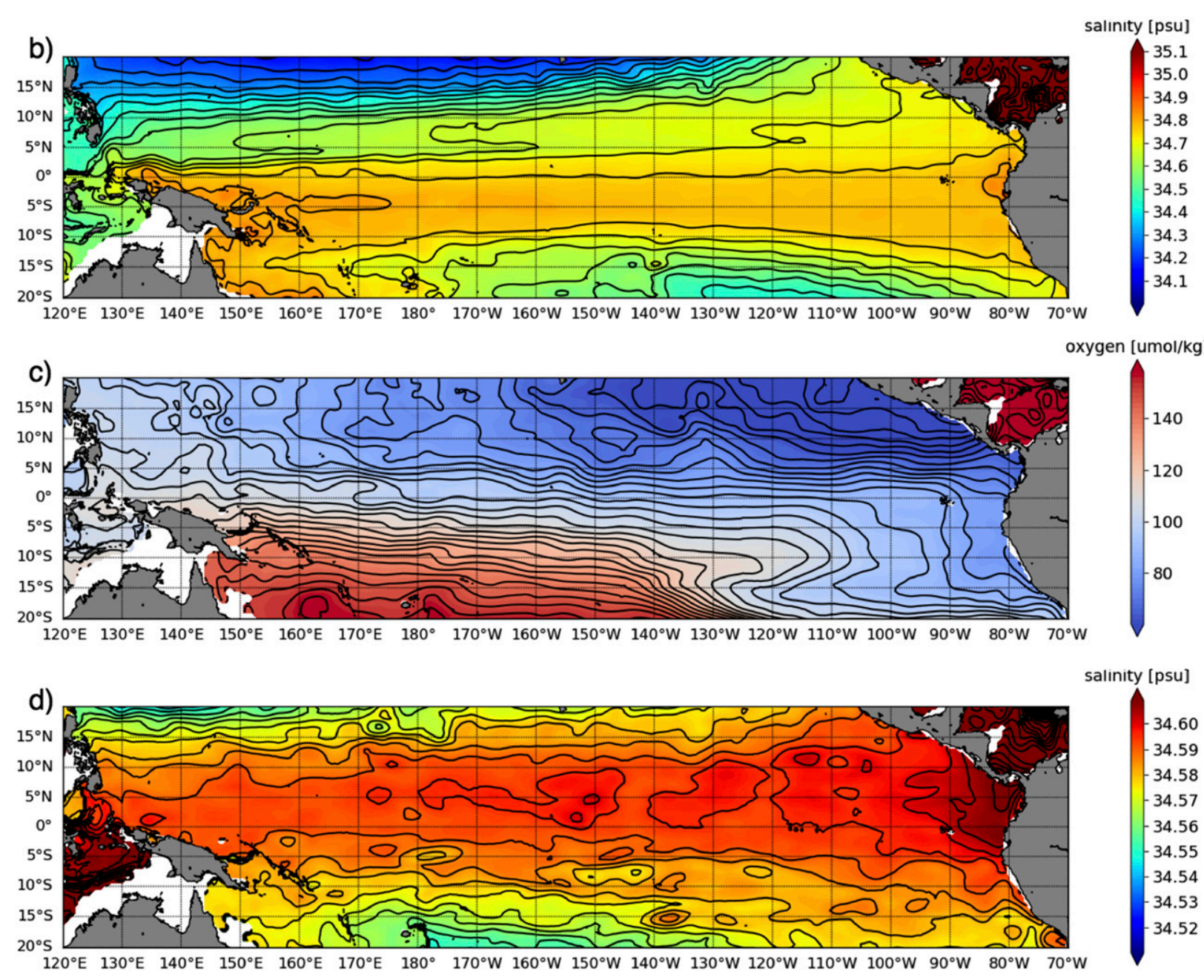

FIG. 12. Background tracer fields of (a),(c) oxygen and (b),(d) salinity from CSIRO Atlas of Regional Seas (Ridgway et al. 2002). Shown in (a) is the integration between isopycnals 1026.4 and $1026.9 \mathrm{~kg} \mathrm{~m}^{-3}$, a typical layer for LLSCs; contours are every $10 \mu \mathrm{mol} \mathrm{kg}{ }^{-1}$. (b) As in (a), but for salinity; contours are every $0.01 \mathrm{psu}$. Shown in (c) is the integration between isopycnals 1027.4 and $1027.6 \mathrm{~kg} \mathrm{~m}{ }^{-3}$, a typical layer for LLICs; contours are every $5 \mu \mathrm{mol} \mathrm{kg}{ }^{-1}$. (d) As in (c), but for salinity, contours are every $0.001 \mathrm{psu}$.

presence of the $\mathrm{OMZ}$ in the eastern part of the basin and the supply of oxygen-rich waters from the western boundary currents (Figs. 12a-c). Our observations show that the oxygen signature depends on the different systems of jets.

The EUC and the first and second Tsuchiya jets carry oxygen-rich waters (sections $3 \mathrm{~b}$ and $4 \mathrm{a}, \mathrm{b}$ ). The oxygen anomalies associated with the jets are observable from the western boundary (Figs. $4 \mathrm{~b}$ and 6), supporting the idea that the EUC and Tsuchiya jets are fed by the oxygen-rich waters from the Solomon Sea in the upper and lower thermocline, as first suggested by Tsuchiya (1981). Given the width of the Pacific ocean $(14500 \mathrm{~km})$ 
and the speed of the zonal jets $\left(5 \mathrm{~cm} \mathrm{~s}^{-1}\right)$, the time needed for a particle to travel from west to east is about 9 years, long enough for turbulent diffusion and biological processes to erode the oxygen anomaly from $120 \mu \mathrm{mol} \mathrm{kg}^{-1}$ at $165^{\circ} \mathrm{E}$ to $40 \mu \mathrm{mol} \mathrm{kg}^{-1}$ at $95^{\circ} \mathrm{W}$ (Fig. 9a). Weak anomalies are still observed in the eastern Pacific, suggesting that these jets are an important source of ventilation for the OMZ.

In the equatorial Pacific, the eastward EDJs and upper SICC and NICC are also associated with oxygen anomalies (Figs. 8 and 10) that have a larger amplitude in the western part of the basin and above $\sim 1500 \mathrm{~m}$. This raises the question of the main source of oxygenrich waters transported by these jets. Above $1200 \mathrm{~m}$, the western boundary current carries oxygen-rich waters from the southern ocean and might provide a source of ventilated waters to these eastward jets (see in Fig. $5 \mathrm{~b}$ section $157.5^{\circ} \mathrm{W}$, the two western boundary stations). In addition, the presence of the $\mathrm{OMZ}$ in the eastern part of the basin and in the upper $900 \mathrm{~m}$ provide a large-scale zonal gradient (Fig. 12a) that likely enhances oxygen anomalies in the basin interior due to advective processes (Fig. 13a). Deeper however, the large-scale background gradient is mainly meridional (Fig. 12c) and the bathymetry can prevent direct supply from the western boundary. The Solomon Sea is connected to the equator by two main pathways: the Vitiaz Strait (closed below $1200 \mathrm{~m}$ ), and the Solomon Strait, whose waters are blocked by a seamount reaching $2000-\mathrm{m}$ depth located at $157^{\circ} \mathrm{E}$. An oxygen supply of the eastward jets (EDJs and S-NICC) by the western boundary current seems thus more difficult below $2000 \mathrm{~m}$. This may explain why there are no clear oxygen anomalies in their cores.

In the off-equatorial LLSC system, the oxygen signature is hard to detect and varies from one cruise to another. This lack of coherency can have two explanations. First, the lack of coherency of the jets themselves. Indeed, whereas EDJs, EUC, and Tsuchiya jets are permanent features of the circulation, off-equatorial LLSCs are weaker and subject to high variability (Cravatte et al. 2017; Qiu et al. 2013a). They may contribute to the ventilation more sporadically (Czeschel et al. 2011). Second, the background gradient has both zonal and meridional components at these depths (Fig. 12a) and is prone to emphasize both advection and mixing mechanisms. The resulting tracer pattern may thus look more complex.

Finally, in the LLIC system, below $1000 \mathrm{~m}$, the jets are systematically associated with staircase structures at different times and longitudes [sections $3 b(4)$ and $4 c$ ]. Staircase profiles are compatible with the observed meridional large-scale gradient in oxygen (Fig. 12c) in the presence of isopycnic inhomogeneous mixing mechanisms (Fig. 13d).

\section{Conclusions and perspectives}

Based on high-resolution in situ data, this study aims at better describing the physical and hydrological properties associated with the jet-structured middepth tropical ocean circulation. Our study has shown that (i) in agreement with previous studies, the close equatorial jets including the EUC, first and second Tsuchiya jets, EDJs, upper NICC, and SICC, are associated with oxygen anomalies and transport oxygen-rich waters from the oxygen-rich western boundary (between the thermocline and $1500 \mathrm{~m}$ ) toward the OMZ in the eastern basin. This confirms the importance of simulating them correctly in models aiming to accurately represent the OMZ ventilation processes. In addition, this calls for a deeper investigation of the water sources for these jets. The sources of the EUC have been well documented since the seminal paper by Tsuchiya et al. (1989) (Grenier et al. 2011), but the pathways and precise origin of waters feeding the NICC, SICC and EDJs are less documented and deserve further study. (ii) In the off-equatorial LLSC system, the signature of the jets is more difficult to detect. Ventilation can occur intermittently but is much harder to quantify because of the possible latent characteristic of these jets. Its precise quantification would require more systematic measurements than scarce cruise transects. The increasing number of Argo floats with oxygen sensors may open a perspective to pursue this work. (iii) In the deeper LLICs, we have discovered, in the western Pacific, the presence of two sharp fronts, distant of about $400 \mathrm{~km}$ from each other and extending over more than $2500 \mathrm{~m}$ (from $500 \mathrm{~m}$ down to $3000 \mathrm{~m}$ ) for three tracers (potential vorticity, salinity, and oxygen).

Investigating the zonal continuity of these frontal structures, we have found that they are observed from $165^{\circ} \mathrm{E}$ to at least $110^{\circ} \mathrm{W}$ and from $20^{\circ} \mathrm{S}$ to $10^{\circ} \mathrm{N}$ at each location where an eastward jet is observed, resulting in staircase meridional profiles. We have interpreted the presence of these staircase profiles as the possible result of some localized mixing processes. This finding is compatible with theories explaining the maintenance of zonal jets by turbulent mixing. Potential vorticity staircases had already been predicted by these theoretical or numerical studies (McIntyre 2008). But it is the first time, that observations corroborate these theories in the ocean and extend it to other tracers, supporting that isopycnal mixing is an effective process and a major ingredient for the equilibration of the jets. We also suggested that LLICs do not contribute to ventilation by direct advection. This does not, however, exclude an indirect role of these jets on the 


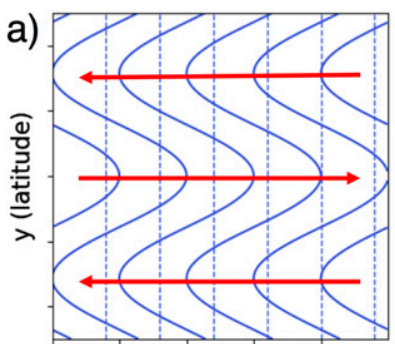

x (longitude)

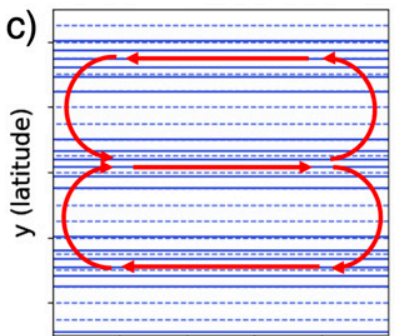

x (longitude)

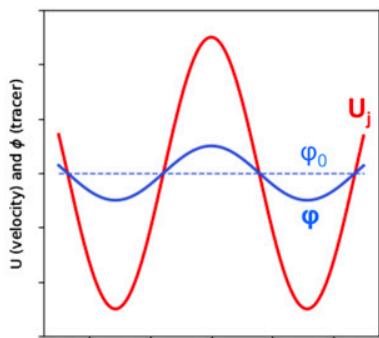

y (latitude)

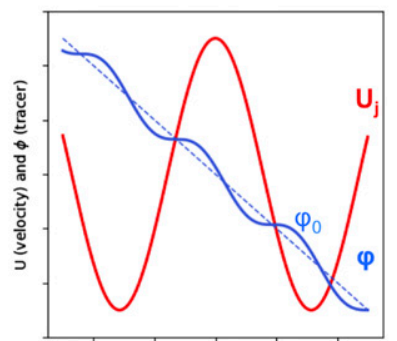

y (latitude)

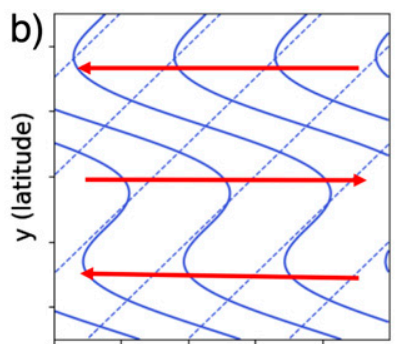

x (longitude)

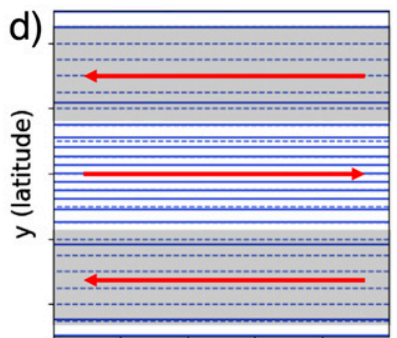

x (longitude)

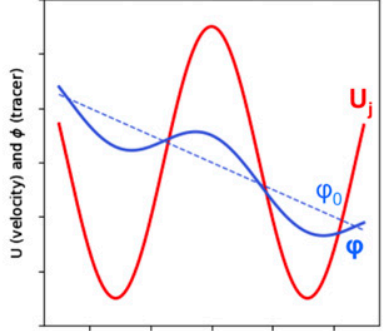

y (latitude)

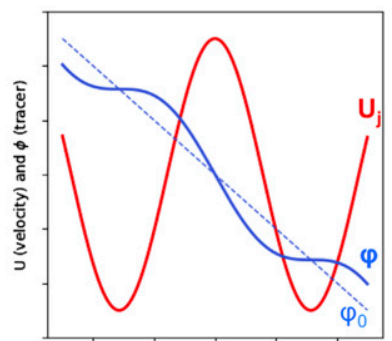

y (latitude)

FIG. 13. Background tracer field deformation in presence of physical processes. (left) Map of the initial tracer field (dashed) and its deformation (solid) under physical processes associated with zonal jets (red). (right) Meridional profiles of tracer field values $\varphi$ (and its background value $\varphi_{0}$ ) and zonal velocities $U$. (a) Zonal advection in zonal background gradient. (b) Zonal advection in slanting background gradient. (c) Recirculation gyres and diffusion in meridional background gradient. (d) Localized mixing in meridional background gradient (shaded areas represent mixing regions).

local oxygen budget of the OMZ by mesoscale processes (mixing, eddy activity).

The different structuring of the tracer fields showing up sometimes as alternating minima and maxima and sometimes as alternating frontal and uniform regions can possibly be explained by the relative importance of the competitive mechanisms (advection and mixing) according to the dominant background large-scale forcing gradient. But other mechanisms and in particular oxygen consumption can also explain these differences, as high biological activity (respiration, degradation of organic matter) takes place. Finally, the permanence of the structures suggests that in any case, a long-term equilibrium must exist between the processes at play.

This study raises further questions on the consequences of the presence of mixing and large-scale frontal structures in the deep ocean. It questions in particular the ability of these jets to create barriers to meridional water masses transport, mixing, and erosion, which could impact the ocean heat budget, ecosystems, or global overturning circulation (Baldwin et al. 2007; Kiko et al. 2017). The deep jets systems require thus increased attention as it may play a crucial role in shaping the oceanic landscape.

Acknowledgments. This work and the CASSIOPEE cruise (https://doi.org/10.17600/15001200) were supported by the French national programme LEFE/INSU, within the project ZEBRE. The authors deeply thank the crew of the R/V Atalante, and the engineers, especially from the IRD IMAGO and DT-INSU team (F. Baurand, J. Grelet, F. Perault, E. de St-Leger, P. Rousselot, N. Lamande, E. Morris, R. Heux) and scientists (G. Eldin, J. Verron, A. Ganachaud, M. Duran, S. Lal, S. Durrieu de Madron, C. Grit-Saout) who carefully sampled, recorded, and processed the data used in this paper during the CASSIOPEE cruise. They also wish to thank Kristene MacTaggart and Gregory Johnson from NOAA/PMEL for providing the TAO cruises oxygen data. The authors thank the CCHDO project (https://cchdo.ucsd.edu/) and the PIs of the available cruises, who deliver high quality global hydrographic data, hence allowing data to have multiple lifes. This study has also been possible thanks to the amount of Argo data, collected and made freely available by the International Argo Program and the national programs that contribute to it. The Argo Program is part of the Global Ocean Observing System (Argo 2000). The authors thank M. Ollitrault, J.-P. Ranou, and other contributors for making the ANDRO Atlas available (https://doi.org/10.17882/47077), and the CSIRO Marine Laboratories for making the CARS climatology available. The authors are grateful to Eric Firing, who provided access to L-ADCP data used in this study and insightful suggestions. They wish to deeply thank him and an anonymous reviewer whose comments have significantly improved the manuscript. This work also benefited from fruitful discussions with P. Brandt, L. Thomas, and P. Haynes. 


\section{REFERENCES}

Ascani, F., E. Firing, P. Dutrieux, J. P. McCreary, and A. Ishida, 2010: Deep equatorial ocean circulation induced by a forceddissipated yanai beam. J. Phys. Oceanogr., 40, 1118-1142, https://doi.org/10.1175/2010JPO4356.1.

,-- J. P. McCreary, P. Brandt, and R. J. Greatbatch, 2015: The deep equatorial ocean circulation in wind-forced numerical solutions. J. Phys. Oceanogr., 45, 1709-1734, https:// doi.org/10.1175/JPO-D-14-0171.1.

Baldwin, M. P., P. B. Rhines, H.-P. Huang, and M. E. McIntyre, 2007: The jet-stream conundrum. Science, 315, 467-468, https://doi.org/10.1126/science.1131375.

Berloff, P., I. Kamenkovich, and J. Pedlosky, 2009: A mechanism of formation of multiple zonal jets in the oceans. J. Fluid Mech., 628, 395-425, https://doi.org/10.1017/S0022112009006375.

Bostock, H. C., B. N. Opdyke, and M. J. Williams, 2010: Characterising the intermediate depth waters of the pacific ocean using $\delta^{13} \mathrm{C}$ and other geochemical tracers. Deep-Sea Res. I, 57, 847-859, https://doi.org/10.1016/j.dsr.2010.04.005.

Brandt, P., V. Hormann, B. Bourlès, J. Fischer, F. A. Schott, L. Stramma, and M. Dengler, 2008: Oxygen tongues and zonal currents in the equatorial atlantic. J. Geophys. Res., 113, C04012, https://doi.org/10.1029/2007JC004435.

— , and Coauthors, 2012: Ventilation of the equatorial Atlantic by the equatorial deep jets. J. Geophys. Res., 117, C12015, https://doi.org/10.1029/2012JC008118.

— the ventilation of oxygen minimum zones with a focus on the eastern tropical North Atlantic. Biogeosciences, 12, 489-512, https://doi.org/10.5194/bg-12-489-2015.

Cabré, A., I. Marinov, R. Bernardello, and D. Bianchi, 2015: Oxygen minimum zones in the tropical pacific across CMIP5 models: Mean state differences and climate change trends. Biogeosciences, 12, 5429-5454, https://doi.org/10.5194/bg-12-5429-2015.

Cravatte, S., W. S. Kessler, and F. Marin, 2012: Intermediate zonal jets in the tropical pacific ocean observed by Argo floats. J. Phys. Oceanogr., 42, 1475-1485, https://doi.org/10.1175/ JPO-D-11-0206.1.

— E. Kestenare, F. Marin, P. Dutrieux, and E. Firing, 2017: Subthermocline and intermediate zonal currents in the tropical Pacific Ocean: Paths and vertical structure. J. Phys. Oceanogr., 47, 2305-2324, https://doi.org/10.1175/JPO-D-170043.1.

Czeschel, R., L. Stramma, F. U. Schwarzkopf, B. S. Giese, A. Funk, and J. Karstensen, 2011: Middepth circulation of the eastern tropical south pacific and its link to the oxygen minimum zone. J. Geophys. Res., 116, C01015, https://doi.org/10.1029/2010JC006565.

,,-- R. A. Weller, and T. Fischer, 2015: Circulation, eddies, oxygen and nutrient changes in the eastern tropical south pacific ocean. Ocean Sci., 11, 455-470, https://doi.org/10.5194/ os-11-455-2015.

d'Orgeville, M., B. L. Hua, and H. Sasaki, 2007: Equatorial deep jets triggered by a large vertical scale variability within the western boundary layer. J. Mar. Res., 65, 1-25, https://doi.org/ 10.1357/002224007780388720.

Dietze, H., and U. Löptien, 2013: Revisiting nutrient trapping in global coupled biogeochemical ocean circulation models. Global Biogeochem. Cycles, 27, 265-284, https://doi.org/10.1002/gbc.20029.

Dritschel, D., and M. McIntyre, 2008: Multiple jets as PV staircases: The Phillips effect and the resilience of eddy-transport barriers. J. Atmos. Sci., 65, 855-874, https://doi.org/10.1175/ 2007JAS2227.1.
- and R. Scott, 2011: Jet sharpening by turbulent mixing. Philos. Trans. Roy. Soc. London, 369A, 754-770, https:// doi.org/10.1098/rsta.2010.0306.

Duteil, O., F. U. Schwarzkopf, C. W. Böning, and A. Oschlies, 2014: Major role of the equatorial current system in setting oxygen levels in the eastern tropical atlantic ocean: A highresolution model study. Geophys. Res. Lett., 41, 2033-2040, https://doi.org/10.1002/2013GL058888.

Eden, C., and J. Willebrand, 1999: Neutral density revisited. Deep-Sea Res. II, 46, 33-54, https://doi.org/10.1016/S0967-0645(98)00113-1.

Eriksen, C. C., 1981: Deep currents and their interpretation as equatorial waves in the western pacific ocean. J. Phys Oceanogr., 11, 48-70, https://doi.org/10.1175/1520-0485(1981) $011<0048$ :DCATIA $>2.0$. CO 2 .

Fieux, M., and F. Webster, 2017: The Planetary Ocean. EDP Sciences, 578 pp.

Firing, E., 1987: Deep zonal currents in the central equatorial pacific. J. Mar. Res., 45, 791-812, https://doi.org/10.1357/ 002224087788327163.

_ S. E. Wijffels, and P. Hacker, 1998: Equatorial subthermocline currents across the Pacific. J. Geophys. Res., 103, $21413-21423$, https://doi.org/10.1029/98JC01944.

Furue, R., J. P. McCreary Jr., Z. Yu, and D. Wang, 2007: Dynamics of the southern Tsuchiya jet. J. Phys. Oceanogr., 37, 531-553, https://doi.org/10.1175/JPO3024.1.

$\longrightarrow,-$, and — 2009: Dynamics of the northern Tsuchiya jet. J. Phys. Oceanogr., 39, 2024-2051, https://doi.org/10.1175/ 2009JPO4065.1.

Galperin, B., and P. L. Read, Eds., 2019: Oceans. Zonal Jets: Phenomenology, Genesis, and Physics, Cambridge University Press, 46-72.

Gill, A., 1974: The stability of planetary waves on an infinite betaplane. Geophys. Astrophys. Fluid Dyn., 6, 29-47, https:// doi.org/10.1080/03091927409365786.

Gouriou, Y., and J. Toole, 1993: Mean circulation of the upper layers of the western equatorial Pacific Ocean. J. Geophys. Res., 98, 22 495-22 520, https://doi.org/10.1029/93JC02513. , and Coauthors, 2001: Deep circulation in the equatorial Atlantic Ocean. Geophys. Res. Lett., 28, 819-822, https:// doi.org/10.1029/2000GL012326.

_- T. Delcroix, and G. Eldin, 2006: Upper and intermediate circulation in the western equatorial Pacific Ocean in October 1999 and April 2000. Geophys. Res. Lett., 33, L10603, https:// doi.org/10.1029/2006GL025941.

Grenier, M., S. Cravatte, B. Blanke, C. Menkes, A. Koch-Larrouy, F. Durand, A. Mélet, and C. Jeandel, 2011: From the western boundary currents to the Pacific Equatorial Undercurrent: Modeled pathways and water mass evolutions. J. Geophys. Res., 116, C12044, https://doi.org/10.1029/2011JC007477.

Hua, B. L., F. Marin, and R. Schopp, 2003: Three-dimensional dynamics of the subsurface countercurrents and equatorial thermostad. Part I: Formulation of the problem and generic properties. J. Phys. Oceanogr., 33, 2588-2609, https://doi.org/ 10.1175/1520-0485(2003)033<2588:TDOTSC >2.0.CO;2.

_ , M. D'Orgeville, M. D. Fruman, C. Menesguen, R. Schopp, P. Klein, and H. Sasaki, 2008: Destabilization of mixed Rossby gravity waves and the formation of equatorial zonal jets. J. Fluid Mech., 610, 311-341, https://doi.org/10.1017/S0022112008002656.

IOC, SCOR, and IAPSO, 2010: The international thermodynamic equation of seawater - 2010: Calculation and use of thermodynamic properties. Intergovernmental Oceanographic Commission, Manuals and Guides 56, UNESCO, 196 pp., http://www.teos10.org/pubs/TEOS-10_Manual.pdf. 
Johnson, G. C., and D. W. Moore, 1997: The Pacific subsurface countercurrents and an inertial model. J. Phys. Oceanogr., 27, 2448-2459, https://doi.org/10.1175/1520-0485(1997)027<2448: TPSCAA $>2.0 . C O ; 2$.

— E. Kunze, K. E. McTaggart, and D. W. Moore, 2002: Temporal and spatial structure of the equatorial deep jets in the Pacific Ocean. J. Phys. Oceanogr., 32, 3396-3407, https://doi.org/ 10.1175/1520-0485(2002)032<3396:TASSOT>2.0.CO;2.

Karstensen, J., L. Stramma, and M. Visbeck, 2008: Oxygen minimum zones in the eastern tropical Atlantic and Pacific Oceans. Prog. Oceanogr., 77, 331-350, https://doi.org/10.1016/j.pocean.2007.05.009.

Kermabon, C., and Coauthors, 2015: CADYHAC: Chaîne D'ajustage des Donnés D’hydrologie Après Campagne-Documentation utilisateur (v1.1). Tech. Rep. R.INT. ODE/LPO/15-01, IFREMER.

Kessler, W. S., 1999: Interannual variability of the subsurface high salinity tongue south of the equator at $165^{\circ} \mathrm{E}$. $J$. Phys. Oceanogr., 29, 2038-2049, https://doi.org/10.1175/ 1520-0485(1999)029<2038:IVOTSH > 2.0.CO;2.

_ and J. P. McCreary, 1993: The annual wind-driven rossby wave in the subthermocline equatorial Pacific. J. Phys. Oceanogr., 23, 1192-1207, https://doi.org/10.1175/1520-0485(1993)023<1192: TAWDRW $>2.0 . \mathrm{CO} ; 2$.

Kiko, R., and Coauthors, 2017: Biological and physical influences on marine snowfall at the equator. Nat. Geosci., 10, 852-858, https://doi.org/10.1038/ngeo3042.

Langdon, C., 2010: Determination of dissolved oxygen in seawater by winkler titration using the amperometric technique. The GO-SHIP Repeat Hydrology Manual: A collection of expert reports and guidelines, IOCCP Rep. 14, ICPO Publ. Series 134, 18 pp., https:// www.go-ship.org/Manual/Langdon_Amperometric_oxygen.pdf.

Leetmaa, A., and P. F. Spain, 1981: Results from a velocity transect along the equator from 125 to $159^{\circ} \mathrm{W}$. J. Phys. Oceanogr., 11, 1030-1033, https://doi.org/10.1175/1520-0485(1981)011<1030: RFAVTA $>2.0 . \mathrm{CO} ; 2$.

Lukas, R., and E. Firing, 1985: The annual rossby wave in the central equatorial Pacific Ocean. J. Phys. Oceanogr., 15, 55-67, https://doi.org/10.1175/1520-0485(1985)015<0055: TARWIT>2.0.CO;2.

Marin, F., R. Schopp, and B. L. Hua, 2003: Three-dimensional dynamics of the subsurface countercurrents and equatorial thermostad. Part II: Influence of the large-scale ventilation and of equatorial winds. J. Phys. Oceanogr., 33, 2610-2626, https:// doi.org/10.1175/1520-0485(2003)033<2610:TDOTSC > 2.0.CO;2.

, E. Kestenare, T. Delcroix, F. Durand, S. Cravatte, G. Eldin, and R. Bourdalle-Badie, 2010: Annual reversal of the equatorial intermediate current in the pacific: Observations and model diagnostics. J. Phys. Oceanogr., 40, 915-933, https:// doi.org/10.1175/2009JPO4318.1.

McCreary, J. P., P. Lu, and Z. Yu, 2002: Dynamics of the pacific subsurface countercurrents. J. Phys. Oceanogr., 32, 2379-2404, https:// doi.org/10.1175/1520-0485(2002)032<2379:DOTPSC >2.0.CO;2.

McDougall, T. J., 1988: Neutral-surface potential vorticity. Prog. Oceanogr., 20, 185-221, https://doi.org/10.1016/0079-6611(88) 90002-X.

McIntyre, M. E., 2008: Potential-vorticity inversion and the waveturbulence jigsaw: Some recent clarifications. Adv. Geosci., 15, 47-56, https://doi.org/10.5194/adgeo-15-47-2008.

_- 1982: How well do we understand the dynamics of stratospheric warmings? J. Meteor. Soc. Japan, 60, 37-65, https:// doi.org/10.2151/jmsj1965.60.1_37.

McPhaden, M., 2015: Playing hide and seek with el niño. Nat. Climate Change, 5, 791-795, https://doi.org/10.1038/nclimate2775.
Ménesguen, C., B. L. Hua, M. D. Fruman, and R. Schopp, 2009: Dynamics of the combined extra-equatorial and equatorial deep jets in the Atlantic. J. Mar. Res., 67, 323-346, https:// doi.org/10.1357/002224009789954766.

, A. Delpech, F. Marin, S. Cravatte, R. Schopp, and Y. Morel, 2019: Observations and mechanisms for the formation of deep equatorial and tropical circulation. Earth Space Sci., 6, 370386, https://doi.org/10.1029/2018EA000438.

Montes, I., B. Dewitte, E. Gutknecht, A. Paulmier, I. Dadou, A. Oschlies, and V. Garçon, 2014: High-resolution modeling of the eastern tropical pacific oxygen minimum zone: Sensitivity to the tropical oceanic circulation. J. Geophys. Res. Oceans, 119, 5515-5532, https://doi.org/10.1002/2014JC009858.

Morel, Y., J. Gula, and A. Ponte, 2019: Potential vorticity diagnostics based on balances between volume integral and boundary conditions. Ocean Modell., 138, 23-35, https:// doi.org/10.1016/j.ocemod.2019.04.004.

Müller, P., 2006: The Equations of Oceanic Motions. Cambridge University Press, $302 \mathrm{pp}$.

Ollitrault, M., and J.-P. Rannou, 2013: Andro: An argo-based deep displacement dataset. J. Atmos. Oceanic Technol., 30, 759788, https://doi.org/10.1175/JTECH-D-12-00073.1.

_ tion near 1000-m depth. J. Phys. Oceanogr., 44, 384-409, https://doi.org/10.1175/JPO-D-13-030.1.

Picaut, J., and R. Tournier, 1991: Monitoring the 1979-1985 equatorial Pacific current transports with expendable bathythermograph data. J. Geophys. Res., 96, 3263-3277, https:// doi.org/10.1029/90JC02066.

Ponte, R. M., and J. Luyten, 1989: Analysis and interpretation of deep equatorial currents in the central pacific. J. Phys. Oceanogr., 19, 1025-1038, https://doi.org/10.1175/1520-0485(1989)019<1025: AAIODE $>2.0 . \mathrm{CO} ; 2$.

Qiu, B., S. Chen, and H. Sasaki, 2013a: Generation of the North Equatorial Undercurrent jets by triad baroclinic Rossby wave interactions. J. Phys. Oceanogr., 43, 2682-2698, https://doi.org/ 10.1175/JPO-D-13-099.1.

_ D. L. Rudnick, S. Chen, and Y. Kashino, 2013b: Quasi-stationary North Equatorial Undercurrent jets across the tropical North Pacific Ocean. Geophys. Res. Lett., 40, 2183-2187, https://doi.org/10.1002/grl.50394.

_, T. Nakano, S. Chen, and P. Klein, 2017: Submesoscale transition from geostrophic flows to internal waves in the northwestern pacific upper ocean. Nat. Commun., 8, 14055, https:// doi.org/10.1038/ncomms14055.

Reverdin, G., C. Frankignoul, E. Kestenare, and M. J. McPhaden, 1994: Seasonal variability in the surface currents of the equatorial pacific. J. Geophys. Res., 99, 20323-20344, https:// doi.org/10.1029/94JC01477.

Rhines, P. B., 1975: Waves and turbulence on a beta-plane. J. Fluid Mech., 69, 417-443, https://doi.org/10.1017/S0022112075001504.

_ in planetary gyres. J. Fluid Mech., 122, 347-367, https:// doi.org/10.1017/S0022112082002250.

Ridgway, K., J. Dunn, and J. Wilkin, 2002: Ocean interpolation by four-dimensional weighted least squares-Application to the waters around Australasia. J. Atmos. Oceanic Technol., 19, 1357-1375, https://doi.org/10.1175/1520-0426(2002)019<1357: OIBFDW $>2.0 . \mathrm{CO} ; 2$.

Roemmich, D., and J. Gilson, 2009: The 2004-2008 mean and annual cycle of temperature, salinity, and steric height in the global ocean from the argo program. Prog. Oceanogr., 82, 81100, https://doi.org/10.1016/j.pocean.2009.03.004. 
Rowe, G. D., E. Firing, and G. C. Johnson, 2000: Pacific equatorial subsurface countercurrent velocity, transport, and potential vorticity. J. Phys. Oceanogr., 30, 1172-1187, https://doi.org/ 10.1175/1520-0485(2000)030<1172:PESCVT>2.0.CO;2.

Saout Grit, C., A. Ganachaud, C. Maes, L. Finot, L. Jamet, F. Baurand, and J. Grelet, 2015: Calibration of ctd oxygen data collected in the coral sea during the 2012 bifurcation cruise. Mercator Ocean Quarterly Newsletter, No. 52, Mercator Ocean, Ramonville SaintAgne, France, 34-38, https://archimer.ifremer.fr/doc/00272/38321/.

Stramma, L., S. Hüttl, and J. Schafstall, 2005: Water masses and currents in the upper tropical northeast atlantic off northwest africa. J. Geophys. Res., 110, C12006, https://doi.org/10.1029/ 2005JC002939.

, P. Brandt, J. Schafstall, F. Schott, J. Fischer, and A. Körtzinger, 2008: Oxygen minimum zone in the North Atlantic south and east of the Cape Verde islands. J. Geophys. Res., 113, C04014, https://doi.org/10.1029/2007JC004369.

— - G. C. Johnson, E. Firing, and S. Schmidtko, 2010: Eastern pacific oxygen minimum zones: Supply paths and multidecadal changes. J. Geophys. Res., 115, C09011, https://doi.org/10.1029/ 2009JC005976.

Theiss, J., 2004: Equatorward energy cascade, critical latitude, and the predominance of cyclonic vortices in geostrophic turbulence. J. Phys. Oceanogr., 34, 1663-1678, https://doi.org/ 10.1175/1520-0485(2004)034<1663:EECCLA > 2.0.CO;2.
Tsuchiya, M., 1975: Subsurface countercurrents in the eastern equatorial pacific ocean. J. Mar. Res., 33, S145-S175.

, 1981: The origin of the Pacific equatorial $13^{\circ} \mathrm{C}$ water. J. Phys. Oceanogr., 11, 794-812, https://doi.org/10.1175/1520-0485(1981) 011<0794:TOOTPE $>2.0$. CO;2.

—, R. Lukas, R. A. Fine, E. Firing, and E. Lindstrom, 1989: Source waters of the pacific equatorial undercurrent. Prog. Oceanogr., 23, 101-147, https://doi.org/10.1016/0079-6611(89) 90012-8.

Uchida, H., G. Johnson, and K. McTaggart, 2010: CTD oxygen sensor calibration procedures. The GO-SHIP Repeat Hydrology Manual: A collection of expert reports and guidelines, IOCCP Rep. 14, ICPO Publ. Series 134, 17 pp., https://www.go-ship.org/ Manual/Uchida_CTDO2proc.pdf.

Visbeck, M., 2002: Deep velocity profiling using lowered acoustic Doppler current profilers: Bottom track and inverse solutions. J. Atmos. Oceanic Technol., 19, 794-807, https://doi.org/ 10.1175/1520-0426(2002)019<0794:DVPULA > 2.0.CO;2.

Wyrtki, K., and B. Kilonsky, 1984: Mean water and current structure during the Hawaii-to-Tahiti Shuttle Experiment. J. Phys. Oceanogr., 14, 242-254, https://doi.org/10.1175/1520-0485(1984) $014<0242$ :MWACSD $>2.0 . \mathrm{CO} ; 2$.

Youngs, M. K., and G. C. Johnson, 2015: Basin-wavelength equatorial deep jet signals across three oceans. J. Phys. Oceanogr. 45, 2134-2148, https://doi.org/10.1175/JPO-D-14-0181.1. 